Marc Biedermann

\title{
Braucht die EU Lobbying-Gesetze? Annäherungen an eine schwierige Frage
}


Das Europainstitut der Universität Basel ist ein rechts-, politik- und wirtschaftswissenschaftliches Zentrum für interdisziplinäre Lehre und Forschung zu europäischen Fragen. Neben einem einjährigen, praxisbezogenen und interdisziplinären Nachdiplomstudium zum Master of Advanced European Studies und dem Vertiefungsstudium Major in Conflict and Development werden spezielle Weiterbildungskurse angeboten. In der Forschung werden

in Zusammenarbeit mit benachbarten Instituten sowohl fachspezifische wie multidisziplinäre Themen bearbeitet. Das Europainstitut ist als Ansprechpartner für Politik, Wirtschaft und Verwaltung beratend tätig.

Marc Biedermann hat nach dem Studium der Soziologie in Bielefeld und Paris im Oktober 2004 erfolgreich den einjährigen Studiengang zum Master of Advanced European Studies absolviert. Während eines zweimonatigen Praktikums im Brüsseler Büro eines deutschen Industrieverbandes konnte er interessante Einblicke in die Interessenvertretung auf europäischer Ebene gewinnen, die ihn zur vorliegenden Arbeit inspirierten.

Kontakt: marc.biedermann@gmx.net

\section{Inhaltsverzeichnis}

$1 \quad$ Einleitung

1.1 Darlegung der Fragestellung

6

1.2 Aufbau der Arbeit

$2 \quad$ Lobbying und Demokratie

2.1 Was ist Lobbying - Begriffbestimmungen und Abgrenzungen

2.2 Die Funktion von Lobbying im demokratischen System

2.3 Lobbying in der öffentlichen Meinung

2.4 Verschiedene Formen und Techniken on Lobbying

3.1 Der Stellenwert von Lobbying im politischen System der EU

3.2 Lobbying im Mehrebenensystem der EU Die Lobbying-Akteure bei der EU Die Adressaten von Lobbying in der EU Erfolgsfaktoren für das Lobbying in Brüssel 
4.1 Das Problem der Legitimierung 34

4.2 Lobbyisten als Informationslieferanten 36

4.3 Legitimitätsgewinn für Kommission durch breite Konsultationen?

4.4 Transparenz als notwendige Voraussetzung für Legitimation

4.5 Die Repräsentativität der angehörten Interessen

4.6 Rechenschaftspflicht für Lobbyisten

5.1 Hintergründe der

Regulierungsdiskussion

5.2 Selbstregulierung

5.3 Gesetzliche Regulierung

\section{Einleitung}

Obwohl Lobbying, also die Vertretung von Interessen gegenüber Entscheidungsträgern ${ }^{1}$, seit jeher mit Politik verbunden ist, scheint es im öffentlichen Bewusstsein bisweilen vernachlässigt zu werden. Wenn von Lobbyisten die Rede ist, dann häufig in einem negativen Kontext, etwa im Zusammenhang mit Spendenskandalen oder Betrugsvorwürfen. Dass aber z.B. die großen Wirtschaftsverbände oder Umweltschutzorganisationen im Prinzip nichts anderes als Lobbying betreiben, wird nicht immer in dieser Deutlichkeit zum Ausdruck gebracht. In der allgemeinen Wahrnehmung scheint ein diffuses und verzerrtes Bild vom Lobbyisten vorzuherrschen: $\mathrm{Er}$ agiert in einer rechtlichen Grauzone und versucht mit nicht immer sauberen Mitteln, (wirtschaftliche) Partikularinteressen durchzusetzen. Demgegenüber stehen die Gemeinschaftsinteressen, die sich durch Mehrheitsentscheide manifestieren und als ehrbares Ziel politischen Handelns gesehen werden. Diese Gegenüberstellung hält einer genaueren Betrachtung nicht stand, wenn man bedenkt, dass sich das Gemeinschaftsinteresse aus einer Vielzahl von partikularen, teils widersprüchlichen und konkurrierenden Interessen zusammensetzt und dadurch einem stetigen Wandel unterworfen ist. Die Auslotung des Gemeinwohls ist die Essenz einer pluralistischen Demokratie, in der der Vertretung von Interessen eine vitale Funktion im Rahmen der Entscheidungsfindung zukommt.

Auch in der (politik)wissenschaftlichen Diskussion scheint das Phänomen des Lobbyismus erst in den 90er Jahren des vergangenen Jahrhunderts allmählich an Beachtung gewonnen zu haben. Trotzdem muss man immer noch feststellen, dass es im Vergleich zu seiner praktischen Relevanz im politischen Tagesgeschäft nur mäßig erschlossen ist. ${ }^{2}$ Dies wird nicht zuletzt damit zusammenhängen, dass ein nicht unerheblicher Teil der spezifischen Lobbying-Tätigkeit hinter den Kulissen abläuft. Dies bedeutet auch einen erschwerten Zugang 
zu Datenmaterial, weshalb empirische Studien selten sind.

Doch dies beginnt sich seit einiger Zeit zu wandeln, da viele neuere Lobbyisten mit einem gewandelten Selbstverständnis auftreten, sich dann auch lieber als Politikberater, Public Affairs Professional o. ä. bezeichnen und ihre Tätigkeit als legitim und ganz im Sinne des demokratischen Systems betrachten und dies auch so kommunizieren. Parallel dazu hat auch die Wissenschaft - wie bereits angedeutet - ein stärkeres Interesse am Lobbying entwickelt und begonnen, die verschiedenen Facetten zu analysieren. Die gesteigerte Aufmerksamkeit für die organisierte Interessenvertretung ${ }^{3}$ - gerade in Europa - hängt auch damit zusammen, dass sie auf der Ebene der europäischen Union eine gewichtige Rolle spielt. So wird die Behauptung vertreten, nirgends sei Lobbying so stark in die Regulierung und Entscheidungsfindung miteinbezogen wie in Brüssel, wofür sich eine Reihe von Argumenten finden lässt. ${ }^{4}$ Fakt ist, dass Lobbyismus für die europäische Integration zugleich funktional und problematisch ist. Ohne eine aktive Partizipation der Interessengruppen bei der Politikgestaltung wäre eine Entwicklung, wie sie die EU erfahren hat, aufgrund der sehr beschränkten Ressourcen und Kapazitäten der Institutionen und der immensen Tragweite des Projektes nicht möglich gewesen. Andererseits wird das vielbeschworene Problem des Demokratiedefizits der EU durch die lange Zeit weitgehend unreglementierte und dadurch unter Umständen unausgeglichene Interessenvertretung noch verstärkt. 5

\section{$1.1 \quad$ Darlegung der Fragestellung}

Eine Ausgangsüberlegung im Vorfeld dieser Arbeit war die Frage, warum trotz ihrer Relevanz relativ wenig über die konkrete und alltägliche Lobbyarbeit in der Europäischen Union bekannt ist und warum immer noch dieses eher negative Image vorherrscht. Ein plausibler Grund dafür scheint zu sein, dass in diesem Bereich ein Mangel an Transparenz zu beobachten ist, der unter anderem die demokratische Legiti- mität solcher Machenschaften in Frage stellt. Interessanterweise wird Lobbying in den USA in einem viel positiveren Sinne gesehen und hat dort einen unbestrittenen Platz im politischen Geschehen. ${ }^{6}$ Da es dort anders als in Europa eine dezidierte Gesetzgebung bezüglich Lobbying gibt, kann - trotz der vielen Verschiedenheiten zwischen den politischen Systemen - vermutet werden, dass im unterschiedlichen Regulierungsgrad ein Grund für die divergenten Konnotationen liegt.

In dieser Arbeit soll einerseits untersucht werden, welche Funktionen Lobbying in der Europäischen Union erfüllen soll und erfüllen kann, und worin andererseits die möglichen Probleme in diesem Zusammenhang liegen können. Damit eng verknüpft ist die Frage der demokratischen Legitimierung organisierter Interessenvertretung: Wie kann gewährleistet werden, dass eine prinzipielle Chancengleichheit zwischen privaten und öffentlichen Interessen gegeben ist? Kann der „Markt“ die Vertreter und Adressaten von Interessen effektiv zusammen bringen, oder ist mit Wettbewerbsverzerrungen zu rechnen? Die Frage ist also nicht, ob organisierte Interessen vertreten werden sollen, sondern in welcher Form dies geschehen soll.

Die Debatte über eine Form von Regulierung für den Bereich der Interessenvertretung wird auch immer dann wieder aktuell, wenn ein Fall von ungerechtfertigter Einflussnahme bekannt wird oder illegitime Verstrickungen z.B. zwischen Wirtschaft und Politik aufgedeckt werden. In Bezug auf die Europäische Union entwickelte sich etwa Anfang der 90er Jahre eine verstärkte Diskussion um die Reglementierung von Lobbying, die bis heute u.a. aufgrund der institutionellen Weiterentwicklung der EU nicht abgeschlossen ist. ${ }^{7}$ Ein vorläufiges Ergebnis dieser Diskussion ist der Ansatz der Regulierung durch Selbstverpflichtungen, wie er zur Zeit in der EU vornehmlich praktiziert wird. Die Kernfrage dieser Arbeit besteht darin, inwiefern diese Art der Regulierung in der Lage ist, die zuvor erarbeiteten Anforderungen an den Lobbyismus zu gewährleisten und wo eventuell weitergehende Maßnahmen in Erwägung gezogen werden müssen. In 
den Bereich dieser Fragestellung fällt nicht nur die Regulierung der Interessenvertreter, sondern auch der Adressaten von Lobbying. Da die Behandlung beider Seiten jedoch den vorgegebenen Rahmen sprengen würde, stehen im Folgenden die Lobbying-Akteure im Vordergrund der Betrachtungen.

\subsection{Aufbau der Arbeit}

In einem ersten Schritt werden in Kapitel 2 die für die Fragestellung relevanten allgemeinen Aspekte von Lobbying diskutiert. Zunächst wird eine Definition des Begriffes Lobbying vorgenommen und die verschiedenen vorzufindenden Konzepte einander gegenüber gestellt und verglichen. Darauf folgt eine skizzenhafte Analyse der Funktionen, die Lobbying in einem politischen System zukommen, verbunden mit der Frage, welche Schlüsse sich daraus für die Fragestellung ergeben. Im dritten Teil des zweiten Kapitels wird untersucht, welches Image Lobbying in der Öffentlichkeit hat, und wie dies zustande kommt. Im letzten Teil dieses Kapitels schließlich werden verschiedene Formen und Techniken von Lobbying vorgestellt, die dann im folgenden Kapitel mit Bezug auf die EU und die vorliegende Fragestellung teilweise vertieft werden.

Das dritte Kapitel befasst sich mit den Spezifika des Lobbying bei den Institutionen der EU, die im Mittelpunkt des Interesses dieser Arbeit stehen. Zunächst wird der besondere Stellenwert von Lobbyismus in Brüssel aufgezeigt und die Gründe dafür analysiert, um dann die Besonderheiten von EU-Lobbying und die Unterschiede zu nationalstaatlichen Bedingungen herauszuarbeiten. Dazu gehört das Mehrebenensystem der EU, dessen Bedeutung für die Interessenvertretung aufgezeigt wird, um in den beiden folgenden Abschnitten einerseits die Akteure und andererseits die Adressaten von Lobbying zu beschreiben und in diesem System zu verorten.

Im vierten Kapitel wird dann die Frage der Legitimation von Lobbying diskutiert und dadurch eine Grundlage erarbeitet, auf der Anfor- derungen an eine Regulierung aufgestellt werden können. Die beiden zentralen Punkte sind hier Transparenz der Vorgänge und Repräsentativität der vertretenen Interessen. Die damit verbundenen Probleme werden aus Sicht der Akteure und der Adressaten von Lobbying betrachtet.

Das fünfte Kapitel schließlich widmet sich dann der Regulierung von Lobbying in der EU. Aufbauend auf die bis dahin angestellten Überlegungen wird untersucht, welche Ansätze es gibt und wo die jeweiligen Vor- und Nachteile liegen. Besonderes Augenmerk wird dabei auf die Politik der Europäischen Kommission bezüglich dieser Frage gelegt. 


\section{Lobbying und Demokratie}

\subsection{Was ist Lobbying - Begriffbestimmungen und \\ Abgrezungen}

Um die im ersten Kapitel dargelegte Fragestellung gewinnbringend zu bearbeiten, ist zunächst eine möglichst griffige Definition von Lobbying zu leisten. Nur wenn deutlich wird, welche Akteure und Verfahren Gegenstand der Betrachtung sind, kann eine sinnvolle Diskussion der Frage der Regulierung erfolgen. So wird denn auch das Definitionsproblem als eine der Ursachen für die Schwierigkeiten bei bisherigen Ansätzen der Regulierung auf europäischer Ebene genannt. ${ }^{8}$ Fällt es schon auf nationalstaatlicher Ebene nicht immer leicht festzulegen, welche Aktivitäten als Lobbyismus betrachtet werden sollen, so liegt es auf der Hand, dass auf europäischem Niveau zusätzliche Probleme durch das Aufeinandertreffen von unterschiedlichen nationalen politischen Kulturen entstehen. Dennoch soll im Folgenden versucht werden, eine für das Ziel der Arbeit hinreichende Eingrenzung vorzunehmen und vor allem auch eine Abgrenzung zwischen den verschiedenen Konzepten zu erreichen. Bleibt vorweg zu sagen, dass dies nicht immer in vollem Umfang möglich ist, da sich die Begriffe teilweise überlappen und sich in der Literatur in manchen Fällen konkurrierende Beschreibungen finden.

Über den Ursprung der heutigen Bedeutung des Begriffs „Lobbying" gibt es in der Literatur verschiedene Angaben, als gesichert gilt jedoch die sprachliche Herkunft des Wortes: „Lobby" leitet sich ab vom lateinischen "labium" und bedeutet soviel wie Vorhalle bzw. Wartehalle. ${ }^{9}$ Gemeinhin wird angenommen, dass die heute geläufige Bedeutung des Begriffs Lobbying als die interessengeleitete Beeinflussung von politischen Entscheidungsträgern im 19. Jahrhundert in den USA entstanden ist und auf die Interessenvertreter zurück geht, die in der Lobby des amerikanischen Kongresses auf die Abgeordneten warteten. ${ }^{10}$ Es bleibt zu betonen, dass sich unabhängig von der Begriffsbildung das Phänomen der gezielten Beeinflussung von Politikern wesentlich weiter zurückverfolgen lässt und sich vermutlich parallel mit der Entstehung von politischen Systemen entwickelt hat. Van Schendelen (2003: 302) vermutet, der Grund für diese langandauernde Namenlosigkeit könnte darin bestehen, dass Lobbyismus so etwas wie die Crux der Politik sei, für die man keine eigene Bezeichnung brauchte. Unbestritten ist die Entfaltung einer Sogwirkung von Machtzentren, und dies nicht erst in der modernen Demokratie, wie wir sie heute kennen. ${ }^{11}$

Eine aktuelle und brauchbare Definition der verschiedenen Kriterien von Lobbying liefert Köppl:

- „Beeinflusst werden legislative Entscheidungen von Behörden und offiziellen Institutionen und zwar

- durch Personen, die selbst nicht Teil des Entscheidungsprozesses sind. ${ }^{12}$

- Diese Beeinflussung muss gewollt und beabsichtigt sein und wird

- über spezielle Kommunikationsinstrumente bewerkstelligt.

- Lobbying zielt auf die punktuelle Beeinflussung spezifischer Sachentscheidungen ab, nicht jedoch auf anhaltende Mitgestaltung der (staats-)politischen Rahmenbedingungen“" (Köppl 1998: 2f., zit. n. Teuber 2001: 117).

Eine prägnantere aber zugleich offenere Definition liefert Fischer (1997: 35). Für inn ist Lobbying schlicht „der Versuch der Beeinflussung von Entscheidungsträgern durch Dritte“. Ungeachtet der genauen Definition lässt sich beobachten, dass der Begriff des Lobbyismus im Laufe der Zeit eine Erweiterung und Verschiebung seiner Bedeutung erfahren hat. Ehemals bezog er sich auf verdeckte, eher illegitime Formen der Einflussnahme von undurchsichtigen Interessenvertretern auf einzelne Abgeordnete. Heute hingegen umfasst der Begriff - und dies im angloamerikanischen Raum stärker als etwa in Europa, 
wo die ältere Bedeutung noch häufiger zu erkennen ist - professionalisierte und legale Arten der Entscheidungsbeteiligung. ${ }^{13}$ "Er [der Begriff, M.B.] oszilliert insofern zwischen legitimen, institutionalisierten und verborgenen Formen der Beeinflussung von AmtsträgerInnen" (Schunter-Kleemann 2003: 194).

Im deutschen Sprachraum wird im Zusammenhang von Lobbying oft die etwas neutraler klingende Bezeichnung "Interessenvertretung" verwendet, vor allem, wenn von der politischen Arbeit von Verbänden die Rede ist. Etwas unspezifischer wird dann manchmal auch von „Verbandsmarketing"14 gesprochen, nicht zuletzt um damit eine steigende Professionalisierung in diesem Bereich zu betonen. Auf die (Neo-)Korporatismus-Debatte, die sich mit der Beteiligung von Verbänden an der Formulierung und Ausgestaltung staatlicher Politik befasst, kann hier nicht näher eingegangen werden. ${ }^{15}$

Grundsätzlich können drei Arten von Lobbying unterschieden werden: ${ }^{16}$ Erstens gibt es "legislatives Lobbying“ (Gesetzgebungs-Lobbying), bei dem es darum geht, die gesetzlichen Normen und somit die Rahmenbedingungen im Sinne der Auftraggeber zu beeinflussen. Beim „anwendungsorientierten Lobbying“ (Vollzugs-Lobbying) ist das Ziel die Beeinflussung von spezifischen Einzelentscheidungen von öffentlichen Instanzen, z.B. bei Fragen der Wettbewerbspolitik. Drittens gibt es das „Fonds-Lobbying“ (Subventions-Lobbying), bei dem Interessengruppen versuchen, die Verteilung von Subventionen und Unterstützungsprogrammen zu ihren Gunsten zu beeinflussen. Hierbei sind marketing-ähnliche Strategien verbreiteter als bei den anderen Lobbyingarten.

Eine andere Unterscheidung aus den USA bezüglich des Ansatzpunktes von Lobbying findet auch in Europa zunehmend Verbreitung, jene zwischen Inside-, Outside- und Grass-roots-Lobbying. ${ }^{17}$ Unter Inside-Lobbying versteht man das direkte Lobbying bei den politischen Entscheidungsträgern und ihren Mitarbeiterstäben. Outside-Lobbying dagegen zielt auf das Umfeld der politischen Entscheidungsträger oder auf relevante Meinungsführer aus Wissenschaft, Medien und anderen Bereichen und wird oft unter dem Begriff Public Affairs subsumiert (s. nächster Absatz). Eine Unterform des Outside-Lobbying ist das sogenannte Grass-roots-Lobbying, bei dem versucht wird, mit Hilfe von Basis-Kampagnen großflächige Mobilisierung zu erreichen und dadurch Einfluss auf politische Entscheidungen zu nehmen.

Wird schon unter Lobbying nicht immer das gleiche verstanden, trifft das in noch größerem Maße für den Begriff „Public Affairs (Management)" zu, nicht zuletzt deshalb, weil er noch relativ neu ist. Wertet man die vorhandene Literatur aus, so fällt auf, dass nicht selten eine Abgrenzung zum klassischen Lobbying versucht und diesem Betätigungsfeld ein moderner Anstrich gegeben wird, um es vom manchmal etwas verstaubt anmutenden Lobbying abzuheben. ${ }^{18} \mathrm{Ge}-$ nerell wird unter Public Affairs (PA) Management eine umfassende (politische) Kommunikationstätigkeit verstanden, die Elemente der Öffentlichkeitsarbeit mit solchen der Interessenvertretung verbindet. Folgende Beschreibung von PA ist hilfreich:

„Das aktive Management der externen Beziehungen eines Unternehmens oder einer Organisation, vor allem mit Regierungen, Behörden, Parlamenten und gesellschaftlichen Gruppen vom Umweltschutzverband bis zur Nachbarschaftsinitiative, aber auch der Medien abseits der Produkt- und Marken-PR oder Investor Relations. Ziele: a) Verbesserung des allgemeinen wirtschaftlichen Klimas durch die Beeinflussung von Politik und Öffentlichkeit. b) Begrenzung negativer Auswirkungen der Aktivitäten der Politik. Public Affairs wenden sich anders als das Lobbying nicht nur an Politiker und Beamte, sondern auch an eigene Arbeitnehmer, Nachbarn, Verbraucher und örtliche Interessengruppen" (Althaus 2001: 368).

Ein wesentliches Merkmal von PA im Unterschied zum klassischen Lobbying besteht darin, dass dieses oft von eigenständigen Agenturen betrieben wird, die für verschiedene Auftraggeber arbeiten und 
daher unterschiedliche (und unter Umständen auch konkurrierende) Interessen vertreten (Auftragslobbying). Althaus spricht von „Söldnern der Politik" (Althaus 2002: 236), deren Loyalität nur solange andauert, wie das Honorar fließt. Für Unternehmen und Organisationen kann ein Outsourcing der Interessenvertretung an eine PA-Agentur lohnenswert sein, da so Spezialisierungs- und Kostenvorteile genutzt werden können.

Ein weiterer verwandter Begriff ist Politikberatung; im deutschsprachigen Raum wird darunter ursprünglich die wissenschaftliche Beratung politischer Entscheidungsträger verstanden. Die Träger von Politikberatung, in erster Linie Experten aus Forschungs- und Beratungsinstituten, unterstützen ihre Adressaten bei der Vorbereitung und Evaluierung von politischen Programmen und erfüllen dadurch vor allem zwei Funktionen: Information und Legitimation. ${ }^{19}$ Zunehmend wird mit Politikberatung aber auch solche Zusammenarbeit bezeichnet, die sich auf unspezifischere Formen der Expertise und Erfahrung stützt oder auf einem persönlichen Vertrauensverhältnis basiert. Es ist offensichtlich, dass eine neutrale, rein wissenschaftliche Beratung von Politikern nicht vorausgesetzt werden kann, sondern immer die Möglichkeit besteht, dass dahinterliegende Interessen die Expertise beeinflussen oder zumindest selektiv wirken. Oder - anders ausgedrückt - es kommt zu einer Vermischung von Sach- und Wertaussagen. Besonders anschaulich wird das bei einigen Think Tanks, die sich einer gewissen politischen oder wirtschaftlichen Gruppe zuordnen lassen oder gar von ihr finanziert bzw. unterstützt werden.

Wird im englischen Sprachraum von „political consultants“ gesprochen, ist damit meist ein freiberuflicher Berater gemeint, der oftmals parteigebunden agiert und für konkrete Aufträge, z.B. Wahlkämpfe, andere Kampagnen oder Meinungsforschung engagiert wird.

Eine weitere Form öffentlicher Kommunikation wird als Public Relations bezeichnet, größtenteils synonym wird der eingedeutschte Begriff „Öffentlichkeitsarbeit“ verwendet. PR ist in allen Lebensberei- chen anzutreffen und scheint heutzutage für fast alle sozialen Zusammenhänge unumgänglich. ${ }^{20}$ Eine Abgrenzung zu Werbung und Journalismus fällt häufig schwer, ebenso der Versuch, die Reichweite und Wirkung solcher Maßnahmen abzuschätzen. Auch besteht wenig Einigkeit darüber, ob Public Affairs ein Teil von Public Relations ist, oder ob das Umgekehrte der Fall ist, dies hängt vom jeweiligen Verständnis der Begriffe ab. Nicht nur Unternehmen (in ihrer Rolle als "corporate citizen") und Organisationen greifen auf PR zurück, auch Staaten und Behörden sind darauf angewiesen, ihr Handeln der Öffentlichkeit zu erklären und um Verständnis zu werben, also letztendlich Imagepflege zu betreiben. ${ }^{21}$

Im Unterschied zum klassischen Lobbying, welches versucht, direkt auf die Entscheidungsträger einzuwirken, wird bei PR-Arbeit über die Mobilisierung von gesellschaftlichen Gruppen, der Öffentlichkeit und den Medien indirekt Einfluss ausgeübt. Im Bereich von Public Affairs wiederum scheinen sich beide Formen zu vermischen.

\subsection{Die Funktion von Lobbying im demokratischen System}

In einer pluralistischen, demokratisch organisierten Gesellschaft ist Lobbying ein wesentlicher Bestandteil politischer Entscheidungsbildungsprozesse, manche Beobachter gehen gar soweit, vom Lobbyismus als fünfter Gewalt zu sprechen. ${ }^{22} \mathrm{Um}$ in einer modernen Demokratie zu tragfähigen, von der Mehrheit akzeptierten Entscheidungen zu gelangen, die sich anschließend auch implementieren lassen, ist ein diskursiver Aushandlungsprozess nötig. Habermas (1962: 236) stellte bereits in den 60er Jahren mit Bezug auf Deutschland fest: "Politische Entscheidungen fallen in den neuen Formen eines „bargaining“, das sich neben den älteren Formen des Machtvollzugs: hierarchy und democracy herausgebildet hat". In der Europäischen Union hat sich diese Entwicklung noch beschleunigt. Öffentlichen und privaten Verbänden, Nichtregierungsorganisationen und anderen LobbyAkteuren kommt dabei die Funktion zu, die unter Umständen diffusen 
und unpräzisen Meinungen und Interessen ihrer Klientel zu bündeln und zu kanalisieren, also Komplexität zu reduzieren. Dadurch werden die unterschiedlichen Standpunkte sichtbar und somit verhandelbar und können in den politischen Arenen zur Willensbildung beitragen. ${ }^{23}$

Die zunehmende Komplexität der verschiedenen Politikbereiche in der heutigen Wissensgesellschaft und der damit einhergehende Informationsbedarf als Grundlage für die Regulierung durch den $\mathrm{Ge}$ setzgeber machen es erforderlich, dass dieser mit externer Expertise versorgt wird. Nur so kann eine solide Fundierung politischen Handelns erreicht werden, auch wenn dadurch natürlich die Abhängigkeit von den Informationsgebern und der Korrektheit der Informationen erhöht wird.

Zuverlässige und relevante Informationen sind für den Lobbyisten das höchste Gut, denn damit kann er bei den für inn wichtigen Entscheidungsträgern Zugang erhalten. Wenn die Informationen für den Entscheider wertvoll sind und er sie in seiner Arbeit einsetzen und sich damit nach außen legitimieren kann, wird er sie gegebenenfalls berücksichtigen. Lobbyismus kann also beschrieben werden als eine Art Tauschgeschäft, bei dem Informationen (und politische Unterstützung) gehandelt werden gegen Interessenberücksichtigung bei der Entscheidungsfindung. ${ }^{24}$ Vor diesem Hintergrund muss ein Lobbyist darauf achten, dass seine Informationen verlässlich sind, will er eine längerfristige Beziehung zu seinem Tauschpartner aufbauen und auch in Zukunft Gehör erhalten.

Zusammenfassend lässt sich festhalten, dass Lobbying ein unerlässliches strategisches Instrument von gesellschaftlichen Gruppen darstellt, um die Interessenartikulation im politischen System zu gewährleisten.

\subsection{Lobbying in der öffentlichen Meinung}

Wie im letzten Abschnitt deutlich wurde, ist Lobbying ein fester Be- standteil im demokratischen Entscheidungsprozess, der zur effizienten politischen Willensbildung beiträgt. Dennoch wird immer wieder betont, welch schlechtes Bild von Lobbyismus in der öffentlichen Meinung verbreitet ist. ${ }^{25}$ "Lobbyisten werden als lichtscheue Gnome charakterisiert, die abseits der öffentlichen Bühne eifrig Klinken putzen und ihren Einfluss primär durch die politische Hintertür zur Geltung bringen" (Sebaldt 2002: 81) ${ }^{26}$ Dieses schlechte Image von Lobbying ist im 19. Jahrhundert in den USA entstanden, als daraus ein $\mathrm{Ge}$ schäft zwischen Politikern und mächtigen Persönlichkeiten aus der Gesellschaft geworden ist. Politische Entscheidungen wurden weniger im Plenum gefällt, als vielmehr hinter verschlossenen Türen vereinbart, und der Austausch von Gefälligkeiten und Korruption stellten durchaus übliche Praktiken dar. Die Bedeutung hat sich in den USA jedoch im letzten Jahrhundert gewandelt, und im Vergleich zum europäischen Raum genießt Lobbying im öffentlichen Ansehen einen höheren Stellenwert. Es ist eine verfassungsrechtlich geschützte Aktivität und wird als legitime Partizipation am Entscheidungsprozess betrachtet. ${ }^{27}$ "To lobby“ bedeutet dort schlichtweg, sich für Interessen einzusetzen, politisch Druck zu machen (Lobby-Organisationen oder Verbänden werden auch als „pressure groups“ bezeichnet) und wird in Bezug auf jede Art von Interessenvertretung und ohne einen negativen Beiklang verwendet. ${ }^{28}$ Als Gründe dafür werden einerseits eine relativ konsequente Gesetzgebung (auf Bundesebene seit 1946) und eine zunehmende Professionalisierung der Lobbying-Akteure genannt, andererseits spielen natürlich auch prinzipielle Unterschiede zwischen den Politiksystemen eine Rolle. ${ }^{29}$

In Europa taucht der Begriff Lobbying in der Berichterstattung der Medien oft in einem negativen Zusammenhang auf, z.B. wenn im Rahmen der Spendenaffäre der CDU bzw. der Leuna-Affäre vom „Waffenlobbyisten" Schreiber die Rede ist. Einen ähnlichen Effekt hatte die Affäre Hunzinger, die im Sommer 2002 zum Rücktritt des deutschen Verteidigungsministers Rudolf Scharping beigetragen hat und 
wo die Beziehung zwischen dem PR-Berater Moritz Hunzinger und dem Politiker zweifelhaft war. Diese Vorfälle haben in Deutschland vor allem bei den freischaffenden Lobbyisten für Aufregung gesorgt und die Diskussion um Standesregeln und Selbstkontrolle entfacht. ${ }^{30}$ Ein weiterer Kontext, in dem das Wirken von Lobbygruppen in den Medien zumeist eher negativ dargestellt wird, sind Reformdiskussionen. Organisierte Interessen werden dann - wahrscheinlich nicht immer unberechtigterweise - als Reformblockierer oder -bremsen charakterisiert, die die Besitzstände ihrer Klientel wahren wollen und damit scheinbar unumgängliche Reformen verhindern. Das trifft in manchen Fällen sicherlich zu, lässt aber außer Acht, dass es genauso gut andersherum denkbar und auch beobachtbar ist, dass nämlich Lobbygruppen politische Veränderungen anstoßen, indem sie z.B. Themen aufgreifen, die politisch brisant sind, und öffentliche Informationsarbeit leisten.

Ein grundlegendes Problem im Zusammenhang mit der öffentlichen Wahrnehmung von Lobbying scheint darin zu liegen, dass ein erheblicher Teil davon im Verborgenen abläuft und so der Eindruck entstehen kann, dass demokratische Kontrolle umgangen werden soll. In der Tat ist die Intransparenz der Tätigkeiten von Interessengruppen ein ständiges Problem und widerspiegelt deren ambivalente Haltung gegenüber der Öffentlichkeit. Einerseits sind die Interessenverbände natürlich an einer möglichst großen Publizität ihrer Standpunkte und Forderungen interessiert, denn durch eine unterstützende öffentliche Meinung kann ihren Vorhaben mehr Druck verliehen werden. Andererseits jedoch soll den Konkurrenten möglichst wenig Einblick in die eigene Geschäftssituation und Praktiken gewährt werden, um strategische Vorteile nicht zu verlieren.

\subsection{Verschiedene Formen und Techniken von Lobbying}

Lobbyorganisationen bzw. Interessenverbände haben zwei Hauptaufgaben. Sie müssen einerseits intern die Anliegen und Wünsche ihrer Mitglieder bzw. Auftraggeber koordinieren und aufeinander abstimmen. Dazu gehört auch, die Interessen so zu formulieren, dass sie bei den Adressaten anschlussfähig sind, d.h., dass sie verstanden werden, plausibel sind und berücksichtigt werden können. Andererseits müssen sie nach außen diesen konsolidierten Standpunkt aktiv vertreten und versuchen, damit eine Wirkung zu erzielen. Dies setzt voraus, dass ein Zugang zu den relevanten Stellen besteht und gepflegt wird, worauf weiter unten noch eingegangen wird.

Das Aufgabengebiet von Lobbyorganisationen umfasst im wesentlichen drei Funktionen: Monitoring, Bewertung und Lobbying im engeren Sinne. ${ }^{31}$ Die erste Funktion des Lobbying ist die kontinuierliche Beobachtung der Entwicklung im für die Organisation relevanten Politikfeld. Das aktive Beobachten der Umwelt soll ermöglichen, frühzeitig wichtige Trends zu erkennen und Chancen und Gefahren abzuschätzen. Aufgrund der zunehmenden Informationsflut ist es hierbei entscheidend, adäquat zu selektieren und Wichtiges von Unwichtigem zu unterscheiden. In einem zweiten Schritt gilt es, die gesammelten Informationen zu analysieren und zu bewerten. Dazu gehört, sich mit den Mitgliedern abzustimmen und einen gemeinsamen Standpunkt zu erarbeiten und eine Strategie zu entwickeln. Drittens schließlich erfolgt dann das eigentliche Lobbying, indem versucht wird, die Handlungsstrategie aktiv umzusetzen und auf den politischen Entscheidungsprozess gestaltend oder behindernd einzuwirken.

Eine hilfreiche Unterscheidung bei der Untersuchung von Lobbying ist jene zwischen formellem und informellem Lobbying. Zu den formellen Einflussmöglichkeiten gehört vor allem das Verfassen von Stellungnahmen und Memoranden, mit denen versucht wird, den eigenen Standpunkt möglichst früh und möglichst weitläufig bekannt zu machen. Außerdem kann man zu den formellen Techniken auch die systematische Kontaktpflege zu den Ansprechpartnern in den Behörden zählen. Telefonischer, persönlicher und schriftlicher Kontakt sowie eine ständige räumliche Präsenz am Ort der Entscheidungsfin- 
dung sind Voraussetzung für eine Wahrnehmung der oben erläuterten Funktionen von Lobbyisten.

In Bezug auf die informellen Techniken ist es naturgemäß schwieriger, konkrete Angaben zu machen, da vieles im Verborgenen läuft. Ein beobachtbares Phänomen ist der Versuch der Besetzung von relevanten Positionen in Ausschüssen, Kommissionen und Arbeitskreisen mit Personen aus dem Umfeld der Lobbyorganisation. Es bieten sich dabei sowohl auf dem nationalen als auch auf dem europäischen Niveau eine Reihe von Möglichkeiten, an institutionalisierten und auch informellen Gremien teilzunehmen und den eigenen Standpunkt einzubringen. Des Weiteren muss davon ausgegangen werden, dass auch heute noch gelegentlich Begünstigungen, z.B. in der Form von (finanziellen) Zuwendungen und Vorteilnahme, eingesetzt werden, um Interessen Nachdruck zu verleihen und Entscheidungsträger zu beeinflussen. ${ }^{32}$ Hier sind die Grenzen zwischen erlaubten Annehmlichkeiten und illegalen Maßnahmen (bis hin zur Korruption) oft fließend und es ist daher schwer, diese Abläufe zu erfassen.

\section{Lobbying in der Europäischen Union}

Widmet man sich dem Forschungsfeld des Lobbyismus im Kontext der Europäischen Union, so fällt schnell auf, dass Vergleiche mit der nationalstaatlichen Ebene nur sehr eingeschränkt möglich sind. Die historische Entwicklung der EU und der supranationale Charakter machen dieses politische Gebilde zu einem beispiellosen, in dieser Form einmaligen Phänomen. Dies hat auch dazu geführt, dass sich die Formen des Lobbyismus in diesem Zusammenhang gewandelt haben und einer besonderen Betrachtung bedürfen.

\subsection{Der Stellenwert von Lobbying im politischen System der EU}

Der spezifische Aufbau der EU mit seinen komplexen und für den (politisch durchschnittlich interessierten) Beobachter manchmal nur mühsam zu durchschauenden Entscheidungswegen stellt eine günstige "Gelegenheitsstruktur" für die Interessenvertretung dar. ${ }^{33} \mathrm{An}$ vielen Stellen im politischen Prozess gibt es Ansatzpunkte, um auf die Entscheidungsfindung Einfluss zu nehmen, oft wird dies sogar explizit gewünscht (s. Kap. 3.4). Und wenn es an der einen Stelle nicht gelungen ist, eine Maßnahme im eigenen Sinne zu bearbeiten, so bietet sich oft die Chance, dies auf einer nachgelagerten Stufe erneut zu versuchen, natürlich immer in Abhängigkeit der eigenen Zugangsmöglichkeiten. Doch es kann generell festgehalten werden, dass sich das Institutionengefüge der EU durch eine vergleichsweise große Offenheit für externe Einflussnahme auszeichnet. ${ }^{34}$

Eine dem Lobbyismus ebenfalls förderliche Bedingung kann darin gesehen werden, dass eine zunehmende Dringlichkeit der Lösung von transnationalen Problemen beobachtet werden kann. Dieses Phänomen wird oft mit dem Begriff "Globalisierung" ${ }^{35}$ umschrieben und dafür verantwortlich gemacht, dass wirkungsvolle Entscheidungen für immer häufiger global auftretende Probleme in immer geringe- 
rem Maße im nationalstaatlichen Kontext getroffen werden können. ${ }^{36}$ Oder, anders ausgedrückt: die gegenwärtigen Aufgabenstellungen an die Politik machen nicht an Landesgrenzen halt, die Auswirkungen von einzelstaatlichen Entscheidungen oft jedoch schon.

Diese hohe Dynamik, verbunden mit der beschriebenen Komplexität, hat dazu geführt, dass sich Brüssel als Kapitale und Sitz aller wichtigen EU-Institutionen zu einem Ort mit auffallend hoher Dichte an Lobbyisten entwickelt hat. Manche Beobachter glauben gar, hier den Ort mit der nach Washington zweithöchsten Konzentration an Lobbyisten weltweit ausgemacht zu haben. ${ }^{37}$ So ist es auch nicht verwunderlich, dass von Insidern mit Bezug auf die politische Arena in Brüssel von einem geschäftigen „Basar" gesprochen wird, auf dem jeder versucht, durch geschicktes Taktieren, Koalieren und Verhandeln seine Interessen durchzusetzen und einen möglichst hohen $\mathrm{Ge}$ winn herauszuschlagen.

Es gibt eine Vielzahl von Schätzungen über die Anzahl von Lobbyisten in Brüssel, die je nach Definition und Art der Erhebung variieren. ${ }^{38}$ Nicht alle Lobbyisten arbeiten hauptberuflich als solche und würden sich immer als solche zu erkennen geben bzw. bezeichnen. Es liegt also in der Natur der Sache, dass keine genauen Zahlen vorhanden sind, aber eine Zahl von 10.000 scheint nicht unrealistisch. Und selbst wenn es nur die Hälfte wären, wäre dies immer noch bemerkenswert. Des Weiteren kann man davon ausgehen, dass etwa 2600 Interessengruppen in Downtown Brüssel über ein ständiges Büro verfügen. ${ }^{39}$ Diese Entwicklung hat dazu geführt, dass schon seit längerer Zeit von einem "overcrowding" (Greenwood 1997: 80) gesprochen wird, also einer Überfüllung der Institutionen mit Interessenvertretern, die in manchen Fällen zu einer Verstopfung bzw. Blockierung der Entscheidungskanäle führen kann. Daraus kann ein Bedarf an Regulierung der Einflussnahme erwachsen, um die Arbeitsfähigkeit der EU-Institutionen aufrechtzuerhalten.

Um die lange Tradition und die Tragweite des Verständnisses vom
Stellenwert von Lobbying in der EU deutlich zu machen, lohnt ein Verweis auf den EGKS-Vertrag von 1951. Dort heißt es:

„Die Hohe Behörde [Vorläufer der Kommission, M.B.] kann jederzeit die Regierungen, die verschiedenen Beteiligten (Unternehmen, Arbeitnehmer, Verbraucher und Händler) und ihre Verbände ebenso wie Sachverständige anhören. Die Unternehmen, die Arbeitnehmer, die Verbraucher und die Händler und ihre Verbände sind berechtigt, der Hohen Behörde zu den sie angehenden Fragen Anregungen oder Bemerkungen jeder Art vorzulegen“ (EGKSV, Art. 46, Abs. 1 f., zit. n. Buholzer 1998: 7).

Die Union sieht sich also seit jeher als demokratisch-pluralistische Gemeinschaft und versteht Lobbying als legitimen Beitrag zur Entscheidungsfindung. Und doch hat es lange Zeit gedauert, bis Brüssel die erste Adresse für Lobbyisten in Europa wurde. Denn zunächst verblieb der überwiegende Teil der Kompetenzen zur Politikgestaltung in den Hauptstädten der jeweiligen Mitgliedstaaten und auch in den Bereichen, wo die Gemeinschaft handlungsfähig war, behielten die Einzelstaaten zunächst ein Vetorecht. Und so blieb es für Interessenverbände am einfachsten, ihre Arbeit auf die nationalen $\mathrm{Re}$ gierungen und Behörden zu beschränken und das bekannte Terrain zu bearbeiten. Dies änderte sich jedoch mit der zunehmenden Integration, spätestens mit der Gründung der Europäischen Union durch den Vertrag von Maastricht 1992 und der (laut Vertrag vorgesehenen) Vollendung des Binnenmarktes im gleichen Jahr.

\subsection{Lobbying im Mehrebenensystem der EU}

Ein wesentliches Charakteristikum des EU-Lobbying besteht darin, dass es sich dem Mehrebenensystem der EU angepasst hat. ${ }^{40}$ Die Kompetenzen zum Regieren sind auf verschiedenen Ebenen angesiedelt und je nach Politikbereich variieren die Zuständigkeiten. Für Lobbyisten bedeutet dies, dass je nach Art des Vorhabens eine andere Strategie gewählt werden muss, um etwas bewirken zu kön- 
nen. Auch die Interessenvertretungen haben sich auf verschiedenen Ebenen organisiert: es gibt zum einen die schon länger bestehenden nationalen Verbände (die sich je nachdem wieder in verschiedene fachliche oder geographische Sektoren aufteilen) und mittlerweile in fast allen wichtigen Bereichen europäische Dachverbände (eine genauere Betrachtung der verschiedenen Akteure erfolgt im nächsten Abschnitt). Dort haben sich die nationalen Verbände zusammengeschlossen, um ihre Kraft zu bündeln und mit einer Stimme bei den EU-Institutionen vorzusprechen und somit nicht zuletzt dem Problem des overcrowding entgegenzutreten.

Um seine Ziele effektiv zu vertreten, muss ein Verband versuchen, alle relevanten Ansatzpunkte zu nutzen. Die nationale Sektion muss bei den Institutionen des eigenen Mitgliedstaates für den Standpunkt werben, das Verbindungsbüro in Brüssel wird versuchen, mit den nationalen EU-Abgeordneten und Kommissionsbediensteten Kontakt zu wahren und der europäische Dachverband schließlich sucht den Zugang zu den höchsten Stellen im Entscheidungsprozess. Lobbying auf europäischem Niveau geschieht also - zumindest wenn es professionell gehandhabt wird - ebenfalls in einem Mehrebenensystem, in dem es gilt, die Struktur- und Entscheidungsprobleme zu antizipieren und den adäquaten Ansatzpunkt zu finden. ${ }^{41}$ Ein gutes Zusammenspiel zwischen nationalen Mitgliedsverbänden und europäischen Spitzenverbänden kann aufwendig sein, ist aber unerlässlich, um zur richtigen Zeit am richtigen Ort zu sein und dadurch zum Erfolg zu kommen.

\subsection{Die Lobbying-Akteure bei der EU}

Im folgenden Abschnitt werden kurz die vier verschiedenen Arten von Lobbying-Akteuren, die im Umfeld der EU arbeiten, vorgestellt. Die Darstellung orientiert sich an der Typisierung von Greenwood (2003:

7 ff.), lässt sich aber so ähnlich auch bei anderen Autoren finden.

Die erste Gruppe bilden staatliche Akteure unterhalb der Regie- rungsebene. Regionale und kommunale Verwaltungseinheiten haben zwar mit dem Ausschuss der Regionen eine institutionalisierte Form der Interessenvertretung, da dieser aber nur beratende Kompetenzen hat und nicht direkt auf die Entscheidungen der EU einwirken kann, unterhalten viele solcher Untereinheiten aus den Mitgliedstaaten eine eigene Interessenvertretung in Brüssel. Dabei ist natürlich zu beachten, dass deren Lobbyingtätigkeit in großem Maße davon abhängt, inwieweit sie auf nationalem Level autonom handlungsfähig sind. So haben etwa die Bundesländer im föderalistischen System der Bundesrepublik Deutschland eine relativ starke Stellung, und entsprechend sind sie auch alle mit teils beachtlicher Stärke in Brüssel vertreten..$^{42}$ Schätzungsweise gibt es über 100 Vertretungen von subnationalen Behörden in Brüssel. ${ }^{43}$

Private und öffentliche Unternehmen bilden die zweite große Gruppe von Lobbying-Akteuren. Laut Nugent (2003: 281) gibt es ca. 250 Lobby-Büros von Firmen in Brüssel, viele davon sind multinationale Unternehmen. Die Lobbyarbeit dieser Firmen ist zwar oft auch eingebunden in nationale Wirtschaftsverbände und europäische Dachverbände, dennoch ist es anscheinend lohnenswert, daneben noch eine eigene Vertretung vor Ort zu unterhalten. Die eigenständige Lobbyarbeit hat natürlich den Vorteil, dass man sich nicht mit anderen Akteuren absprechen muss, sondern gezielt seine ganz spezifischen Interessen verfolgen kann, wenn es sein muss auf diskrete Art und Weise. Die Autoindustrie ist ein Beispiel für einen Sektor, indem autonomes und direktes Lobbying der Unternehmen in Brüssel sehr verbreitet ist, haben doch praktisch alle großen Autofirmen eine Vertretung in Brüssel.

Eine weitere wichtige Lobbygruppe bilden die nationalen Interessenverbände, von denen die großen, und zwar etwa 170, ein eigenes Verbindungsbüro in Brüssel unterhalten (vgl. Greenwood 2003: 9). Die kleineren agieren von ihren nationalen Büros aus und/oder über einen europäischen Dachverband. In bestimmten Bereichen, v.a. in 
Geschäfts- und Handelssachen, gibt es auch eine Reihe von Verbänden aus Nicht-EU-Ländern mit einem Ableger in Brüssel. Einer der einflussreichsten ist das EU Committee of the American Chamber of Commerce (AMCHAM-EU).

Als nächstes sind europäische (Dach)Verbände und Organisationen zu nennen, d.h. solche, deren Mitglieder aus mehreren verschiedenen Ländern kommen. Nach einer aktuellen Bestandsaufnahme gibt es in Brüssel derer 768 (vgl. Greenwood 2003: 9). Prinzipiell lassen sich zwei Arten unterschieden: die Vertreter von Wirtschaftsinteressen umfassen ca. $65 \%$, der restliche Anteil verteilt sich auf öffentliche Interessen, Arbeitnehmerinteressen, Umweltschutz, Soziales etc (s. ebd.).

Die Politikbereiche, in denen die privaten bzw. wirtschaftlichen Interessengruppen tätig sind, sind vielfältig und reflektieren alle Themen, die in der EU direkt oder indirekt diskutiert werden. Zu den mächtigsten sogenannten Eurogroups zählen sicher der Ausschuss der berufsständischen landwirtschaftlichen Organisationen der EU (COPA), die Vereinigung der europäischen Industrie- und Arbeitgeberverbände (UNICE) und der Verband der europäischen chemischen Industrie (CEFIC). ${ }^{44}$ Eine weitere, zunehmend wichtiger werdende Gruppe sind die Nichtregierungsorganisationen (NROs, englisch NGOs) und gemeinnützigen Verbände, die sich der Vertretung von öffentlichen bzw. sozialen Interessen widmen und oft als Vertreter der Zivilgesellschaft bezeichnet werden. ${ }^{45}$ Sehr unterschiedlich sind die Gruppen auch in Bezug auf ihre finanzielle Ausstattung: die großen Wirtschaftsverbände verfügen in der Regel über ein beachtliches Budget, während viele Vertreter von öffentlichen bzw. sozialen Interessen und mit einer kleinen Mitgliederbasis über relativ geringe Ressourcen verfügen (s. Kap. 4.5).

Je größer und repräsentativer in Bezug auf seine Klientengruppe ein Verband ist und vor allem je "europäischer" sein vertretener Standpunkt ist, umso bessere Chance hat er, von der Kommission als wichtiger Ansprechpartner bei den Konsultationen im legislativen Prozess anerkannt zu werden. ${ }^{46}$ Kleineren Interessengruppen bleibt dann manchmal (nur) noch der Weg des "sekundären Lobbying“, nämlich der Versuch, mittels größerer Organisationen das eigene Ziel zu verfolgen. ${ }^{47}$ Das zweite Kriterium, welches die Attraktivität für die Kommission (und auch das Parlament) erhöht, ist die Einheitlichkeit und Pointiertheit des unterbreiteten Anliegens und der Wert der vorgelegten Informationen.

Neben den bis jetzt behandelten Akteuren, die alle ihre eigenen Interessen vertreten, oder im Falle der Verbände diejenigen ihrer Mitglieder, die also ein konstantes Aufgabenfeld haben, gibt es diejenigen Lobbyisten, die auftragsgebunden arbeiten (und daher manchmal auch als Auftragslobbyisten bezeichnet werden). Oft handelt es sich dabei um Anwaltskanzleien, die neben ihren klassischen Aufgaben der Rechtsvertretung spezielle Dienstleistungen („Consulting“) im Hinblick auf EU-Themen anbieten. Hinzu kommen die im 2. Kapitel bereits erwähnten Public Affairs Agenturen, die die Interessen ihrer Auftraggeber im Rahmen eines spezifischen Auftrages verfolgen.

\subsection{Die Adressaten von Lobbying in der EU}

In diesem Abschnitt soll nun ein Blick geworfen werden auf die wichtigsten Ansprechpartner, mit denen die oben genannten Lobbyisten zusammenarbeiten. Die Europäische Kommission und das Europäische Parlament stehen dabei ganz klar im Vordergrund, während der Europäische Rat so gut wie keine Rolle spielt und im Ministerrat letztendlich nur über die nationalen Regierungen Einfluss genommen werden kann. Der Fokus dieser Arbeit wird daher - nicht zuletzt um den gegebenen Rahmen einzuhalten - auf Kommission und Parlament liegen.

Der Wirtschafts- und Sozialausschuss und der Ausschuss der Regionen spielen entgegen ihrer ursprünglichen Bestimmung keine bedeutende Rolle auf der europäischen Lobbying-Bühne, schlicht und er- 
greifend deshalb, weil sie kein Mitentscheidungsrecht haben, sondern von den gesetzgebenden Organen nur angehört werden müssen. Es wird größtenteils als effektiver angesehen, direkt bei diesen Organen zu lobbyieren und es kann daher manchmal der Eindruck entstehen, dass diese beiden Ausschüsse nur eine Art Alibi-Funktion einnehmen. Sie können also im weiteren Verlauf der Betrachtung getrost außer Acht gelassen werden. Die Einrichtung des "Sozialen Dialogs“ zwischen den europäischen Sozialpartnern hat zwar institutionelle Aufwertungen erfahren und sich als Vermittlungsinstanz etabliert, wird aber im weiteren aufgrund der Spezifizität der Interessen keine Berücksichtigung finden.

Die Kommission ist „der klassische Anlaufpunkt für Lobbyisten“ (Fischer 1997: 49). Dafür gibt es mehrere Gründe, einer der wichtigsten besteht sicherlich in ihrer starken Stellung im Gesetzgebungsverfahren, wo sie das Initiativmonopol innehat, d.h. das alleinige Recht, Gesetzesvorschläge vorzulegen. Etwa $80 \%$ der von der Kommission ausgearbeiteten Gesetzesentwürfe erfahren im weiteren Verfahren keine wesentlichen Änderungen mehr, so dass ein rechtzeitiges Einwirken durch Interessenvertreter im frühen Stadium der Entstehungsphase vor der schriftlichen Fixierung für das Ergebnis entscheidend sein kann. 48

Des Weiteren gilt die Kommission als Hüterin der Verträge (Kontrolle über Einhaltung und Anwendung des EU-Rechts), als das Exekutivorgan der Union und als Vertreterin des supranationalen Interesses der EU im Rat. Für diese Fülle von Aufgaben steht ihr mit zwischen 20.000 und 30.000 (je nachdem, ob die ausgelagerten Dienste wie z.B. die Betrugsbekämpfung und der administrative Apparat dazugezählt werden) relativ wenig Personal zur Verfügung. ${ }^{49}$ Die Kommission war daher schon immer darauf angewiesen, in ihrer Doppelfunktion als zentrale gemeinschaftspolitische Instanz und als Verwaltungseinrichtung auf externen Sachverstand zurückzugreifen. „Umfassende Anhörungen sind kein neues Phänomen. Die Kommission konsultiert traditionsgemäß externe Interessengruppen bei der Gestaltung ihrer Politik. Für sie gehört die externe Konsultation zur Entwicklung nahezu aller Politikbereiche" (Kommission, 2002: 3).

Konsultationen (so die bevorzugte Bezeichnung der Kommission für ihre Interaktion mit Interessenvertretern) auf breiter Basis ermöglichen ihr auch, das Informationsdefizit über die Situation in den Mitgliedstaaten und den Mangel an Schnittstellen zu den nationalen Administrationen auszugleichen. Diese Offenheit der Kommission für Vorschläge aus den Interessengruppen geht soweit, dass nicht selten komplette Textentwürfe z.B. für eine Richtlinie erwartet werden, die dann teilweise ohne große Änderungen übernommen werden und das gesamte Gesetzgebungsverfahren „überleben“ und verabschiedet werden. ${ }^{50}$

Um möglichst konstant auf die gefilterten Informationen und Auffassungen der Euroverbände zugreifen zu können und den fehlenden intermediären Unterbau zu kompensieren, hat die Kommission - in bester korporatistischer Manier - bereits frühzeitig die Bildung europäischer Verbände angeregt und gefördert, fallweise sogar materiell unterstützt. ${ }^{51}$ Dies verdeutlicht sehr anschaulich die enge Verbundenheit der Kommission mit den Interessengruppen und wie sehr sie darauf angewiesen ist, hochwertige externe Unterstützung zu bekommen.

Ein weiterer Anreiz für die Kommission zur Zusammenarbeit mit den betroffenen Gruppen liegt in der Stärkung ihrer Verhandlungsposition mit den anderen am Gesetzgebungsverfahren beteiligten EU-Organen, die dadurch erreicht werden kann. Ein Vorschlag, der von den Interessengruppen möglichst breit unterstützt wird, hat bessere Chancen, in den Verhandlungen mit dem Parlament und dem Rat Erfolg zu haben, was natürlich im Interesse der Kommission ist, da es ihre Arbeit aufwertet. Außerdem können so frühzeitig mögliche Widerstände abgeschätzt werden, wodurch die erfolgreiche Implementierung erleichtert wird. Doch auch zwischen den 23 Generaldi- 
rektionen innerhalb der Kommission herrscht ein gewisses Maß an Rivalität. „Zwar folgt die Kommission selber dem Kollegialitätsprinzip; faktisch trägt die Kommissionsverwaltung jedoch die Züge einer horizontal ausdifferenzierten bürokratischen Organisation" (Eichener 2000: 293). Damit geht einher, dass sich eine innerorganisatorische Konkurrenz um Status und Anerkennung entwickelt und organisierte Interessen und ihre zur Verfügung gestellten Ressourcen können bei Profilierungsversuchen einer Generaldirektion hilfreich sein. Im Laufe der Zeit hat sich so ein breitgefächertes System der Zusammenarbeit mit Außenstehenden institutionalisiert, v.a. im unüberschaubar komplexen Ausschusssystem, welches in Kap. 4.4 näher beleuchtet wird.

Seit das Europäische Parlament entscheidend an Kompetenzen im Gesetzgebungsverfahren hinzugewonnen hat, ist es als Ziel von Beeinflussungsversuchen für organisierte Interessen wesentlich interessanter geworden. Mit der Einführung des Kooperations- und des Zustimmungsverfahrens durch die Einheitliche Europäische Akte im Jahre 1987 und des Mitentscheidungsverfahrens durch den Vertrag von Maastricht 1993 ist eine erhebliche politische und rechtliche Aufwertung des Parlamentes erfolgt.

Besonders die jeweiligen Mitglieder und vor allem die Vorsitzenden („rapporteur“) der zu allen behandelten Themen eingesetzten Ausschüsse sind ein wichtiges Ziel von Lobbyisten, um ihre Anliegen vorzutragen. Eine institutionalisierte Gelegenheit dafür bieten die sogenannten Hearings, die zu wichtigen Fragen einberufen werden. ${ }^{52}$ Die Parlamentarier (Mitglieder des Europäischen Parlaments - MEPs) sind - ähnlich wie die Kommissionsbeamten - daran interessiert, relevante Informationen in ihre Arbeit einfließen zu lassen, um so die Qualität und Praktikabilität der Ergebnisse zu steigern.

Daneben existieren eine Reihe informeller Praktiken der Einflussnahme, etwa sogenannte „Parlamentarische Abende“ oder „Abgeordnetengespräche", zu denen z.B. die Landesverbände die nationalen Abgeordneten aus einzelnen Fraktionen einladen und versuchen, für heimische Anliegen zu sensibilisieren, oder gezielt gepflegte kontinuierliche Kontakte zu bestimmten Abgeordneten. Außerdem besteht die Möglichkeit der direkten Interessenvertretung über Abgeordnete, die zugleich Mitglied oder Funktionsträger einer Interessenorganisation sind.

Besonders interessant als Anlaufpunkt ist das Parlament für soziale bzw. öffentliche Interessen (die auf der nationalen Ebene zum Teil nur schwach vertreten sind), wie z.B. Verbraucher-, Umwelt- und Arbeitnehmerinteressen, da es sich in diesen Politikbereichen besonders profiliert. Dies könnte damit zusammenhängen, dass es das einzige direkt gewählte Organ der EU ist und so eine gewisse Sensibilität für die „kleinen“ Interessen hat. So wird von diesen gelegentlich versucht, via Parlament die Kommission und den Rat zu beeinflussen. ${ }^{53}$ Außerdem bietet sich dem Parlament in diesen Bereichen die Möglichkeit, sich öffentlichkeitswirksam als Gegenpol zur Kommission und zum Rat zu profilieren (solche Prozesse werden u.a. vom Policy Coalition-Ansatz untersucht) ${ }^{54}$ Attraktiv ist das Parlament für Lobbyisten auch dahingehend, da hier noch interveniert werden kann, wenn die Möglichkeiten bei der Kommission bereits ausgereizt sind. ${ }^{55}$ Dies kann z.B. dann wichtig sein, wenn man erst zu spät von einer Gesetzesausarbeitung bei der Kommission erfahren hat oder die angebrachten Vorschläge dort kein Gehör gefunden haben.

\subsection{Erfolgsfaktoren für das Lobbying in Brüssel}

Zum Schluss dieses Kapitels sollen nun noch kurz einige Faktoren beleuchtet werden, von denen angenommen werden muss, dass sie die Erfolgschancen von Lobbying in Brüssel (wie wahrscheinlich auch an anderen Orten) beeinflussen. Dies soll dazu beitragen, das Verständnis der Interessenvertretung bei der EU zu vertiefen und einige Aspekte der Fragestellung zu verdeutlichen.

Eine elementare Bedingung für erfolgreiche Lobbyarbeit in Brüssel ist der Aufbau und die Pflege eines umfangreichen und diversifizierten 
Netzwerkes (s. auch Kap. 4.4), um kontinuierlich über die aktuellen Entwicklungen orientiert zu sein und den Kontakt zu den wichtigen Ansprechpartnern auf Seiten der Entscheidungsträger zu halten. Lahusen/Jauß (2001: 175 f.) betonen die Bedeutung der persönlichen Ebene von geschäftlichen Kontakten als wesentliches Kennzeichen der Brüsseler Lobbying-Szene. Freundschaftliche und vertrauensvolle Beziehungen erleichtern den Zugang zu Informationen und sind eine gute Grundlage für längerfristige Kooperation.

Unerlässlich ist es auch, über exakte Kenntnisse der Machtstrukturen und Entscheidungswege zu verfügen, um jeweils zu wissen, wo der relevante Ansatzpunkt für eine Intervention liegen kann und wie diese durchzuführen ist. Doch wird auch ein gut funktionierendes Netzwerk nicht immer verhindern können, dass man in manchen Situationen schlichtweg um Zugang kämpfen muss, z.B. wenn es darum geht, in einen Ausschuss bei der Kommission zu kommen.

Äußerst bedeutsam ist auch, beim Lobbyieren das richtige "Timing“ zu wählen, d.h. vor allem möglichst frühzeitig zu versuchen, in den politischen Gestaltungsprozess einzugreifen. Das setzt voraus, dass man gut informiert ist und von den Vorhaben der Institutionen erfährt, bevor diese offiziell bekannt werden und so eventuell noch auf den Entstehungsprozess (also die Phase des sogenannten agenda-setting) einwirken kann. Hier hat man nicht selten die besten Chancen, entscheidenden Einfluss zu nehmen und gewünschte Elemente in der Vorlage unterzubringen bzw. unliebsame zu unterdrücken oder abzumildern.

Weiterhin ist es für einen Lobbyisten unerlässlich, über wertvolle und korrekte Informationen zu verfügen, die seinem Ansprechpartner einen Mehrwert bringen, indem er sie in seine Arbeit einfließen lassen kann. Nur so kann er sicherstellen, für seinen Gegenüber von Interesse zu sein und somit Gehör für seine Anliegen zu finden. Es ist klar, dass diese Informationen mit seinem Anliegen zusammenhängen werden, sie sollten aber so formuliert werden, dass ein Einklang mit dem Allgemeinwohl hergestellt werden kann, um die Chancen der Beachtung zu erhöhen.

Um diese Grundbedingungen professioneller Lobbyarbeit zu gewährleisten, gibt es einige Faktoren, die unerlässlich sind. Dazu gehört die örtliche Nähe zu den Institutionen, also ein Standort in Brüssel, um die Kontakte, gerade auch auf der informellen Ebene, pflegen zu können. Und es ist wichtig, die wichtigsten Sprachen in der EU einigermaßen zu beherrschen, um die spezifischen Dokumente studieren zu können, unter Umständen auch schon bevor sie in der eigenen Sprache vorliegen. Gute Vorbereitung und fachliche Kompetenz im jeweiligen Gebiet kann entscheidend sein, wenn es darum geht, seinen Gesprächspartner vom eigenen Standpunkt zu überzeugen. 


\section{Legitimation von Lobbying}

Im Folgenden sollen nun auf der Grundlage des bisher Erarbeiteten, die in der Einleitung aufgeworfenen Problemkreise der Legitimierung sowie der Regulierung von Lobbying bei der EU diskutiert werden. Diese beiden Bereiche hängen miteinander zusammen und können sowohl analytisch als auch praktisch nicht sauber getrennt werden. Dennoch werden die beiden Fragestellungen zunächst nacheinander bzw. aufeinander aufbauend betrachtet, die Diskussion der verschiedenen Lösungsansätze erfolgt dann jedoch zusammen und nimmt jeweils auf die einzelnen Probleme Bezug.

\subsection{Das Problem der Legitimierung}

Wie bereits deutlich geworden ist, kann Lobbying als legitimer Bestandteil im demokratischen Entscheidungsprozess betrachtet werden. Durch die (organisierte) Interessenvertretung wird es den gesellschaftlichen Gruppen möglich, an den Entscheidungen zu partizipieren, von denen sie dann später betroffenen sein werden. ${ }^{56}$ Doch damit Lobbying auch tatsächlich Partizipation im demokratietheoretischen Sinne bedeutet, müssen einige Bedingungen gegeben sein, die im Folgenden untersucht werden sollen.

Zur Analyse der Legitimation von demokratischen Systemen hat Fritz W. Scharpf (1999: 16 ff.) ein Modell von zwei komplementären Prinzipien entwickelt, jenes der Input- und Output-Legitimation. Die Input-orientierte Perspektive betont die "Herrschaft durch das Volk" und untersucht die Entstehungswege von politischen Entscheidungen. Demnach sind jene Entscheidungen legitim, die den Willen des Volkes widerspiegeln; zentrale Elemente dieser Argumentation sind „Partizipation" und „Konsens“, die sich in Mehrheitsentscheidungen manifestieren (normatives Prinzip der Zustimmung). Aufgrund der Distanz zwischen Entscheidern und Betroffenen - die in der EU in weitaus größerem Maße vorhanden ist als in herkömmlichen staat- lichen Systemen - „muss unter pragmatischen Gesichtspunkten die Rechtfertigung der Mehrheitsherrschaft als Zentralproblem Input-orientierter Theorien demokratischer Legitimation angesehen werden“ (Scharpf 1999: 17). In Bezug auf die EU ist die Frage nach der InputLegitimität problematisch, weil davon ausgegangen werden muss, dass die Union noch weit von einer starken kollektiven Identität entfernt ist, diese jedoch laut Scharpf als Bedingung für die legitimatorische Kraft von Mehrheitsentscheidungen gegeben sein muss. ${ }^{57}$

Dieses Defizit wird teilweise durch die ergänzende Argumentationsperspektive der Output-Legitimität aufgefangen, welche die „Herrschaft für das Volk“ in den Vordergrund stellt. „Danach sind politische Entscheidungen legitim, wenn und weil sie auf wirksame Weise das allgemeine Wohl im jeweiligen Gemeinwesen fördern" (Scharpf 1999: 16). Ein politisches System erhält seine Legitimation in diesem Sinne dadurch, dass es in der Lage ist, einen Output an kollektiven Lösungen für kollektive Probleme zu generieren (funktionales Prinzip der Nützlichkeit). Im Unterschied zur Input-Legitimation ist hierfür nicht unbedingt eine gemeinsame Identität erforderlich, sondern es genügt, wenn in einem System gemeinsame Interessen vorhanden sind.

Obwohl die Perspektive der Input-Legitimation in der Anwendung auf die EU problematisch ist, eben weil diese (noch) nicht mit einem herkömmlichen Staat verglichen werden kann, soll bei der folgenden Analyse der Legitimationsfrage des EU-Lobbying auch diese Blickrichtung Berücksichtigung finden. Und zwar alleine schon deshalb, weil sich die EU in ihrer Selbstbeschreibung als demokratisches System versteht und die beiden Aspekte dieses Legitimationsmodells wenn nicht für sich beansprucht, so doch zumindest langfristig anstrebt. Neben einer Legitimation durch den Output, der auch in der jetzigen Situation schon in vielen Bereichen auszumachen ist, kann in einer längerfristigen Perspektive und mit zunehmender Integration nicht auf eine Legitimation durch demokratische Verfahren verzichtet werden. 


\subsection{Lobbyisten als Informationslieferanten}

Aus der Perspektive der Input-Legitimität von Lobbying bei der EU liegt ein wesentliches Argument in der Bereitstellung von Informationen durch die Interessenvertreter. Mittels der Interessenverbände und anderer Lobby-Akteure entstehen Informationsflüsse, die die Anliegen von den Betroffenen zu den Entscheidern transportieren. Lobbyisten nehmen demnach eine Art Scharnierfunktion ein zwischen gesellschaftlichen Funktionssystemen wie z.B. dem Wirtschaftssystem und dem politischen System. Dies erfordert Übersetzungsarbeit, da diese beiden Systeme nach unterschiedlichen Logiken operieren und unterschiedliche „Sprachen“ sprechen, die nicht ohne weiteres kompatibel sind. Würden die jeweiligen Interessen direkt und ungefiltert in das politische System hineingetragen, wären konstantes Chaos und Überlastung die Folge. Die Entscheidungsträger würden sich entweder abschotten, oder aber eine unhaltbare Behinderung der Abläufe würde eintreten, verursacht durch die ständigen und diffusen Irritationen von außen. Doch die Bereitstellung von relevanten und aufgearbeiteten Informationen ermöglicht es Kommission und Parlament, effektive Entscheidungen zu treffen, deren Umsetzung (größtenteils) auch funktioniert. Dies wiederum trägt zur Erhöhung der Output-Legitimation der Institutionen bei, da die Qualität der Erlasse erhöht werden kann.

Wie bereits angedeutet, hat dieses Argument jedoch nur Bestand, wenn die gelieferten Informationen auch korrekt sind, was nicht selbstverständlich ist, da ja davon ausgegangen werden muss, dass sie immer mit gewissen (partikularen) Interessen verbunden sind und dadurch eventuell verzerrt übermittelt werden. Die Richtigkeit der Informationen kann dadurch gesichert werden, dass unkorrekte Informationen durch den Empfänger sanktioniert werden, wofür es bis jetzt jedoch keinen wirkungsvollen Mechanismus gibt. ${ }^{58}$ Ein Weg der Sanktionierung bestünde darin, dass die betroffene Stelle in der Institution den Lieferanten der mangelhaften Information vom Zugang ausschließt, was von daher gravierend wäre, da dieser ja auf das Wissen über die Entwicklungen in der Institution angewiesen ist, um seine Interessen effektiv vertreten zu können. Der Ausschluss gewisser Interessenvertreter, gerade der großen Verbände, kann jedoch für die Institutionen dahingehend problematisch sein, dass sie - wie gezeigt - oftmals auf den externen Sachverstand angewiesen sind, also eine Art gegenseitiges Abhängigkeitsverhältnis angenommen werden muss.

\subsection{Legitimitätsgewinn für Kommission durch breite \\ Konsultationen?}

Die Kommission hat von jeher mit einem Legitimationsdefizit zu kämpfen, da sie - etwa im Unterschied zum Parlament - kein gewähltes Organ darstellt. Außerdem ist eine relativ große Distanz der Kommission zu den Regulierungsadressaten zu beobachten, verbunden mit einem manchmal gespannten Verhältnis zu den Mitgliedstaaten, auch in der Form der Beziehungen zum Rat. Eine Gelegenheit der Kompensation dieses Defizits besteht möglicherweise in der Steigerung der Input-Legitimität durch eine Konsultation möglichst vieler gesellschaftlicher Interessen- und Anspruchsgruppen im Rahmen von Entscheidungsprozessen. ${ }^{59}$ Es ist offensichtlich, dass solch ein Vorgehen - unbeachtet der Frage des tatsächlichen Legitimationsgewinns - nachteilige Effekte mit sich bringen kann, und zwar vor allem eine Verlängerung der Prozesse und eine Verkomplizierung der Konsensfindung. Je zahlreicher und diversifizierter die beteiligten Interessen sind, desto langwieriger gestalten sich die Verhandlungen und desto kleiner ist vermutlich auch der gemeinsame Nenner, der gefunden werden kann.

Die Bedeutung der Partizipation für die Frage der Legitimität der Entscheidungsbefugnisse wird von der Kommission angeführt, um ihren oft unüberschaubaren, informellen Umgang mit Interessengruppen zu verteidigen und gegen Regulierungsbemühungen zu ar- 
gumentieren (s. Kap. 5.2). So heißt es im Weißbuch „Europäisches Regieren“, in dem u. a. auch die zukünftige Gestaltung der Zusammenarbeit mit gesellschaftlichen Interessen thematisiert wird: „Wie gut, sachgemäß und wirksam die Politik der Union ist, hängt davon ab, inwieweit die Akteure in den Politikgestaltungsprozess - von der Konzipierung bis hin zur Durchführung - einbezogen werden. Verstärkte Teilhabe bewirkt größeres Vertrauen in das Endergebnis und die Politik der Institutionen" (Kommission 2001: 13). Die Pflege von Netzwerken mit subnationalen und gesellschaftlichen Akteuren stellt also einen Versuch der Kommission dar, ihre Distanz zur Bevölkerung zu kompensieren. Sie sieht gar "formlose direkte Kontakte mit den betroffenen Parteien" (Kommission 2002: 3, Hervorhebung M.B.) neben dem Europäischen Parlament sowie dem Wirtschafts- und Sozialausschuss und dem Ausschuss der Regionen als dritte Form der Beziehung zwischen den europäischen Institutionen und der Gesellschaft (vgl. ebd.). Die Kommission ist also bemüht, für Effektivitätssteigerung und Legitimierung zu sorgen, indem sie sich offen gibt, was auch von den kleineren, oftmals benachteiligten Gruppierungen positiv bewertet wird. ${ }^{60}$ Andere Stimmen stehen diesem Versuch des Legitimationsgewinns durch die Einbeziehung der organisierten $\mathrm{Zi}$ vilgesellschaft jedoch kritisch gegenüber, vor allem - und dies nicht wirklich überraschend - die Mitgliedstaaten, da diese einen Rückgang ihres Einflusses zugunsten der NGOs befürchten müssen. So mahnt z.B. die Bundesrepublik Deutschland vor allem demokratietheoretische Bedenken an und verweist auf die fehlende bzw. unklare Legitimation dieser Organisationen, mit denen die Legitimation der EU erhöht werden soll:

„Die von der Kommission als „Zivilgesellschaft" bezeichneten Sozialpartner, NROs und informellen Gruppen nehmen im Rahmen der Artikulation von Interessen von Bürgern und Betroffenen auch gegenüber den europäischen Institutionen eine wichtige Rolle wahr. Ihre Einbeziehung in den gemeinschaftlichen Entscheidungsprozess begründet jedoch keine eigenständige oder ergänzende demokratische Legitimation. Die Konsultation der „Zivilgesellschaft“ im Vorfeld von Entscheidungen kann zwar Transparenz und Effektivität des EU-Handelns verbessern; ihrer Einbeziehung in Entscheidungen oder der Übernahme von Verantwortung im Umsetzungsprozess steht jedoch entgegen, dass die Vertreter dieser Interessenvereinigungen weder über ein demokratisches Wahlmandat verfügen noch parlamentarisch kontrolliert werden, während das Gesamtinteresse durch die Parlamente vertreten wird" (Bundesrepublik Deutschland 2001: 2). ${ }^{61}$

Politische Mitentscheidungsrechte für NGOs wären problematisch, denn in einer Demokratie müssen diese durch Wahlen erworben oder von gewählten Körperschaften verliehen werden. Hart (2003: 71) spricht in Bezug auf diese Frage auch von einem Demokratisierungsparadoxon, in dem sich NGOs befinden: Einerseits tragen sie durch ihre Arbeit in vielen Fällen dazu bei, politische, soziale, kulturelle u.ä. Probleme transparenter zu machen, andererseits handeln sie selbst oft intransparent. Ihre Strukturen sind nicht immer demokratisch und transparent und die Repräsentativität ihrer Interessen kann höchstens durch die Zahl ihrer Anhänger bzw. Mitglieder abgeschätzt werden.

\subsection{Transparenz als notwendige Voraussetzung \\ für Legitimation}

Es ist deutlich geworden, dass Lobbying als Partizipationsform der gesellschaftlichen Interessengruppen im politischen System der EU betrachtet werden kann und damit einen Beitrag leistet zur Mehrung der Input-Legitimation der Union. Bei einer kritischen Betrachtung wird jedoch auch schnell deutlich, dass diese Sichtweise an ihre Grenzen gerät, wenn bestimmte Konditionen der Einflussnahme nicht gegeben sind. Unumgängliche Bedingungen scheinen dabei Transparenz und Offenheit der Interessenvertretung zu sein. Nur wenn allen Interessierten und Betroffenen gleichzeitig bekannt wird, dass ein neues 
Gesetzesvorhaben geplant ist und wer damit befasst ist, besteht auch eine gerechte und gleiche Chance der Partizipation. Ist dies nicht der Fall, sind immer diejenigen im Vorteil, die "näher" dran sind an den Entscheidern und daher schneller und besser vorbereitet reagieren können. Und auch die Öffentlichkeit als generalisierter Adressat der EU-Politik sollte den gleichen Informationszugang haben wie die Interessengruppen, um sich bei Bedarf beteiligen zu können oder ansonsten zumindest über die Entstehung von Entscheidungen informiert zu sein. Das Europäische Parlament als Vertreter der Bürger vermutet, „dass die effiziente öffentliche Bekanntgabe der Identität und des Ausmaßes der Tätigkeit bezahlter Lobbyisten zur Einflussnahme auf EU-Organe im Entscheidungsfindungsprozess das Vertrauen der Öffentlichkeit in die Integrität der EU-Organe eindeutig erhöhen wird" (Europäisches Parlament 2003b: 6).

Über diese Anforderungen scheint sich auch die Kommission im Klaren zu sein: „Die Kommission ist der Auffassung, dass Verwaltungs- und Politikgestaltungsabläufe für die Außenwelt sichtbar sein müssen, wenn sie nachvollzogen werden und glaubwürdig sein sollen. Dies gilt insbesondere für Konsultationsverfahren, die die erste Schnittstelle mit den gesellschaftlichen Interessen darstellen" (Kommission 2002: 17). Daraus folgt, dass die beteiligten Parteien transparent handeln müssen, damit für interessierte Beobachter ersichtlich ist:

- „welche Themen zur Debatte stehen

- welche Mechanismen für die Anhörung angewendet werden

- wer angehört wird und warum

- wodurch die Entscheidungen bei der Politikgestaltung beeinflusst wurden" (ebd.).

Hierbei handelt es sich - betrachtet man die momentanen Abläufe - um hochgesteckte Ziele, deren Erreichen eine tatsächliche Verbesserung bedeuten würde. Denn nach allem, was in der Literatur über Konsultationen der Kommission zu finden ist, laufen diese immer noch zu einem großen Teil informell und selektiv ab. Dies ist auch nicht unbedingt erstaunlich, wenn man bedenkt, über welch lange Zeit diese Praktiken sich entwickelt haben und quasi zu dem gewachsen sind, was man heute beobachten kann. Die Gefahr dabei liegt auf der Hand: Beziehungen zwischen Beamten und Lobbyisten nehmen klientelistische Züge an und das nötige Abstandgebot gerät außer Acht. ${ }^{62}$

Einer der größten Kritikpunkte ist immer wieder das undurchsichtige und unüberschaubare Ausschusswesen der Kommission. ${ }^{63}$ Es gibt eine Vielzahl von verschiedenen Arten von Ausschüssen, je nachdem, um welchen Politikbereich es sich handelt und in welcher Stufe der Politikgestaltung sie angesiedelt sind. Im Allgemeinen wird von Sachverständigenausschüssen oder Expertenausschüssen gesprochen, in denen Gesetzesvorhaben vorbereitet werden. „Their [Generaldirektionen, M.B.] solution is to insource experts from outside, representing larger interest groups and brought together in experts committees. At the moment there are, at estimate, about 1.800 of such committees with 80.000 experts at all, coming fifty-fifty from domestic governments [...] and private organizations (two third profit-oriented and one-third NGO)" (van Schendelen 2003: 303). Für einen Interessenvertreter kann es sehr wertvoll sein, einen Platz in solch einem beratenden Ausschuss zu bekommen, da er so in direkten Kontakt mit den Beamten der Kommission kommt und einen beiderseitigen Informationsfluss herstellen kann. ${ }^{64}$ Dass dieses Ausschusswesen oft alles andere als transparent ist und demokratische Prinzipien in Frage stellt, scheint auch der Kommission bewusst zu sein, wie folgendes Zitat aus dem Weißbuch „Europäisches Regieren“ anschaulich macht:

„Das undurchsichtige System der EU-Sachverständigenausschüsse und die fehlenden Informationen über deren Arbeitsweise tragen nicht unbedingt zu einer positiven Wahrnehmung in der Öffentlichkeit bei. Oft ist nicht klar erkennbar, wer eigentlich die Entscheidungen trifft - Sach- 
verständige oder Politiker. Zudem werden Inhalt und Objektivität der Expertenempfehlungen von einer besser informierten Öffentlichkeit zunehmend in Zweifel gezogen" (Kommission 2001: 25).

Die Deutlichkeit und Offenheit der Selbstkritik ist durchaus überraschend, wenn man sie mit anderen Aussagen der Kommission, etwa über ihre Ansprüche als Exekutivorgan der Union und Vertreterin des Gemeinschaftsinteresses, vergleicht. Dabei muss man sich vor Augen halten, dass das Weißbuch kurz nach der zweiten BSE-Krise erschienen ist, und die damals zu Tage getretenen Versäumnisse der Risikobewertung und des Risikomanagements auf Seiten der Kommission noch sehr präsent waren.

\subsection{Die Repräsentativität der angehörten Interessen}

Transparenz ist eine notwendige Voraussetzung, damit ein weiteres Element auf dem Weg zu verstärkter Input-Legitimation erreicht werden kann, nämlich eine erhöhte Repräsentativität der einbezogenen Interessengruppen. Nur wenn alle gesellschaftlichen Interessen im Rahmen ihrer Möglichkeiten an der Politikgestaltung partizipieren können, kann von einer wirklichen, breit abgestützten Konsensfindung ausgegangen werden. In der Vergangenheit war diese Voraussetzung nicht gegeben, wie auch die Kommission unumwunden zugeben muss: „Dadurch [Mindeststandards, s. Kap. 5.2] würde die Gefahr vermindert, dass sich die Entscheidungsträger allzu einseitig informieren oder dass einzelne Gruppen bei dem Konsultationsprozess aufgrund sektorspezifischer Interessen oder ihrer Staatsangehörigkeit bevorzugt werden, was eindeutig eine Schwäche der gegenwärtigen Methode punktueller Konsultationen ist" (Kommission 2001: 22). In der Tat ist es so, dass von Kennern des Lobbyismus die Konsultationsverfahren in vielen Fällen als wenig repräsentativ beschrieben werden, und dass sie scheinbar in vielen Fällen immer noch auf informellem Wege ablaufen und sich teilweise quasi-klientelistische
Beziehungen gebildet haben. Viele Beobachter sind sich einig, dass (privat)wirtschaftliche Interessen gegenüber öffentlichen bzw. sozialen Interessen überrepräsentiert sind und vermutlich über mehr Einfluss verfügen. ${ }^{65}$ Dies ist nicht unbedingt erstaunlich, ist doch die heutige EU das Ergebnis eines zunächst primär wirtschaftlich ausgerichteten Einigungsprozesses, die Vertreter der Wirtschaftsinteressen können sich also als Teil der europäischen Polity verstehen. ${ }^{66}$ Scheinbar ist es den öffentlichen Interessen jedoch noch nicht in ausreichender Weise gelungen, proportional zum erweiterten Kompetenzfeld der EU an Bedeutung in der politischen Arena dazuzugewinnen, auch wenn Tendenzen in diese Richtung zu erkennen sind. Ob es möglich ist, gleiche Zugangsbedingungen für alle Interessengruppen (oder ein „level playing field“, also ein ausgeglichenes Spielfeld) zu gewährleisten, und wie dies gegebenenfalls erreicht werden könnte, ist eine komplexe Frage, die hier nur gestreift werden kann. Problematisch sind die unterschiedlichen Fähigkeiten der Organisation von Interessen, abhängig von deren Natur. Wie Olson (1968) in seiner Theorie kollektiven Handelns nachweist, haben es kollektive, also in erster Linie öffentliche/soziale Interessen schwerer, Mitgliederanreize zu schaffen. Dies lässt sich zurückführen auf die Nicht-Rivalität und Nicht-Ausschließbarkeit ihrer Leistungen, so dass Einzelne bzw. Unternehmen auch von den Leistungen profitieren, wenn sie der Organisation/dem Verband nicht beitreten, was auch als Free-Rider- bzw. Trittbrettfahrer-Problem bezeichnet wird. ${ }^{67}$ Die Organisation von Interessen ist laut Olson besonders schwierig, wenn die betroffene Gruppe groß und heterogen ist und wenn die Kosten für die Erstellung des Kollektivgutes hoch und die Nutzen für den Einzelnen (scheinbar) gering sind. Diese Faktoren treffen in unterschiedlicher Gewichtung auf öffentliche und gesellschaftliche Interessen zu, was ihre nachteilige Stellung gegenüber den privaten Interessen und damit die Schwierigkeiten der Ausbalancierung verdeutlicht.

Zur Beschreibung der vorherrschenden Strukturen und Prozesse 
innerhalb des Ausschusswesens, wo die Zugangsproblematik besonders deutlich wird, scheint sich das Netzwerk-Konzept anzubieten. ${ }^{68}$ Politik-Netzwerke können verstanden werden als „nicht formal organisierte, durch wechselseitige Abhängigkeiten und gemeinsame Verhaltenserwartungen bzw. Handlungsorientierungen stabilisierte Kommunikationsbeziehungen zwischen Angehörigen von Organisationen, die in politische Prozesse involviert sind“ (Benz 1997: 316). Jachtenfuchs/Kohler-Koch (2002: 14) stellen fest: „Regieren in der EU vollzieht sich in Netzwerken“. Diese These impliziert, dass auch die Lobbyarbeit in Netzwerkstrukturen eingebunden ist und innerhalb der unüberschaubaren Netzwerke der Kommission und der vermutlich etwas kleineren Netzwerke um das Parlament vonstatten geht. Die spezifischen Merkmale eines Netzwerkes werden dann bestimmt durch verschiedene Faktoren, v.a. durch die beteiligten Akteure, deren Funktionen sowie Strategien und die Strukturen, die sich in der Form der Verbindungen zwischen den Mitgliedern etablieren. Bleiben Netzwerke über einen gewissen Zeitraum in ähnlicher Konstellation bestehen, wird es zu einer Institutionalisierung der Strukturen kommen, verbunden mit der Ausprägung von (größtenteils informellen) "Spielregeln“.

Der Netzwerk-Ansatz sensibilisiert für eine Verschiebung bei der Politikgestaltung von hierarchischer Entscheidung (was nicht heißen soll, dass in Netzwerken keine Machtbeziehungen vorkommen) hin zu mehr horizontal gelagerter Aushandlung unter Einbeziehung gesellschaftlicher Akteure. Damit verliert sich auch eine klare Unterscheidung von Steuerungssubjekt und Steuerungsobjekt. Problematisch gestaltet sich jedoch die Frage der Inklusion in solche Netzwerke bzw. der Grad der Offenheit/Geschlossenheit für die verschiedenen Akteure. Da viele wirtschaftliche Interessengruppen schon seit langer Zeit mit der Kommission zusammenarbeiten (s. Kap. 3.4), haben sie ein größtenteils informelles Netzwerk zu den verschiedenen Anknüpfungspunkten in den Generaldirektionen etablieren können, welches neueren und schwächer organisierten Verbänden erst einmal verschlossen bleibt. ${ }^{69}$ Dies muss gar nicht einmal heißen, dass bestimmten Interessengruppen der Zugang zu Netzwerken aktiv verwehrt wird, sondern dass diese über die entscheidenden Vorgänge gar nicht oder erst hinterher erfahren. „[T]he system is loaded in favour of those who know their way around it" (Greenwood 1997: 81). Ein Indiz für die hohe Bedeutung der Informalität der Strukturen und Prozesse der Entscheidungswege und die Wichtigkeit solcherlei Kenntnisse für Lobbyisten ist die Tatsache, dass viele Politiker, wenn sie sich von ihrer Tätigkeit (warum auch immer) zurückziehen, von Lobbyorganisationen liebend gern angestellt werden. Ihr Insider-Wissen ist sehr wertvoll für die neuen Arbeitgeber, so dass solche Seitenwechsel häufig vorkommen. ${ }^{70}$ Potentiellen Missbrauch von vertraulichen Informationen versucht man durch sogenannte „Abkühlungsfristen“ - also Fristen, die zwischen dem Ausstieg aus der Politik und dem Beginn einer Lobbytätigkeit liegen müssen - in den Griff zu bekommen.

\subsection{Rechenschaftspflicht für Lobbyisten}

Neben Transparenz und gleichen Zugangsmöglichkeiten sieht sich die organisierte Interessenvertretung mit einer weiteren Forderung konfrontiert: jener nach Verantwortlichkeit bzw. Rechenschaftspflicht der Lobbyisten. Diese Forderung ist einerseits verständlich, da sie rechtsstaatlichen Grundprinzipien entspricht, andererseits nicht ohne weiteres implementierbar, da in der EU die Zuschreibung von Entscheidungen auf politisch verantwortliche Personen oder politische Parteien nur schwach ausgeprägt ist. „Es wird offensichtlich mit weitreichenden Folgen regiert, aber die dafür Verantwortlichen sind schwer auszumachen und zur Verantwortung zu ziehen" (Jachtenfuchs/Kohler-Koch 2002: 4). Dieser Umstand erleichtert es Lobbyisten, ihre Einflussnahme zu verschleiern und verringert die Wahrscheinlichkeit, für ihr Verhalten Rechenschaft ablegen zu müssen. Denn generell ist zu beobachten, dass in der Politik die Tendenz besteht, Verant- 
wortung nur für (vermeintlich) erfolgreiche Akte zu übernehmen und die Verantwortung für Fehlgeschlagenes zu externalisieren. Auch hier scheint Transparenz ein unabdingbarer Steuerungsmechanismus zu sein, um Fehlentwicklungen zu verhindern.

\section{Regulierung von Lobbying}

Wie im bisherigen Verlauf der Arbeit deutlich wurde, wirft die Betrachtung des Lobbying bei der EU vor dem Hintergrund demokratietheoretischer Überlegungen eine Reihe von Fragen auf. So ist nicht immer eindeutig zu klären, wo die Grenzen legitimer Einflussnahme auf Entscheidungsträger liegen und wer deren Einhaltung kontrolliert. Weiterhin ist fraglich, ob alle gesellschaftlichen Interessen über die gleichen Zugangsbedingungen zu den Institutionen verfügen und somit eine Balance im Wettstreit der Interessen gegeben ist. Es konnte gezeigt werden, dass eine ganz wesentliche Bedingung für demokratieverträgliche Lobbyarbeit in deren Transparenz und Nachvollziehbarkeit für die Öffentlichkeit liegt. Und auch wenn sich viele Akteure in der Union dieser Voraussetzung mittlerweile bewusst sind und einige Maßnahmen in diese Richtung unternommen oder zumindest angedacht wurden, sind wir immer noch ein gutes Stück von transparenter Entscheidungsfindung und -beeinflussung entfernt.

\subsection{Hintergründe der Regulierungsdiskussion}

Diese und andere Fragestellungen mögen dazu beigetragen haben, dass sich Anfang der 90er Jahren eine Diskussion um die Regulierung der Interessenvertretung entwickelt hat, die bis heute nicht abgeschlossen ist. ${ }^{71}$ Neben den allgemeinen, demokratie- und legitimationstheoretischen Fragen haben andere bereits angesprochene Faktoren zu dieser Diskussion beigetragen: Zum einen das Definitionsproblem (s. Kap. 2.1), also die Frage, welche Tätigkeiten überhaupt als Lobbying verstanden werden können und folglich Gegenstand einer eventuellen Regulierung sein sollen, und zum anderen das Problem des overcrowding (s. Kap. 3.1), d.h. die große Zunahme an Lobbyisten und die damit einhergehende Gefahr der Behinderung der Arbeitsabläufe der EU-Organe. Buholzer (1998: 18) beschreibt eine weitere mit dem overcrowding zusammenhängende Entwick- 
lung der 90er Jahre, nämlich der verschärft stattfindende Wettbewerb unter den Interessengruppen, der zu einer Zunahme von unkorrekten Verhaltensweisen von Lobbyisten beigetragen hat. „Darunter fällt etwa das stundenlange Blockieren von Faxmaschinen, das unangekündigte Auftauchen in den Büros der Abgeordneten und Beamten, das Entwenden von internen Dokumenten, der Verkauf derselben zu hohen Preisen, das missbräuchliche Verwenden von offiziellen Logos usw." (ebd.). ${ }^{72}$ Greenwood (1997: 80) berichtet von Problemen im Parlament, wo Abgeordnete sich nicht ausreichend mit den vor den Sitzungen ausliegenden Unterlagen eindecken konnten, da diese bereits von früher eingetroffenen Lobbyisten genommen wurden. Ebenfalls wird berichtet von „bombardment[s] of letters and phone calls from companies" (Europäisches Parlament 2003a: 34) und anderem aufdringlichen Verhalten von Lobbyisten, durch das sich manche Abgeordnete unter Druck gesetzt fühlen.

Im Folgenden sollen nun die verschiedenen zur Diskussion stehenden Regulierungsmodelle analysiert und auf ihre Vor- und Nachteile und ihre Wirksamkeit hin untersucht werden. Im Prinzip stehen sich zwei Regulierungsmodelle gegenüber, die sich wiederum in unterschiedliche Abstufungen bezüglich ihrer jeweiligen Ausprägungen unterteilen lassen. Auf der einen Seite steht das Konzept der Selbstregulierung, welches darauf setzt, dass sich die beteiligten Akteure, also Lobbyisten und deren Adressaten, eigenmächtig auf Verhaltensregeln einigen und diese durchsetzen. Demgegenüber steht die Ansicht, dass es gesetzlicher Regelungen bedarf, um die Anforderungen an demokratieverträgliches Lobbying zu verwirklichen und zu kontrollieren.

\subsection{Selbstregulierung}

Die Vertreter des Modells der Selbstverpflichtung gehen davon aus, dass es - zumindest auf lange Sicht - zum eigenen Vorteil der Interessenvertreter ist, sich auf Regeln für angemessenes Verhalten innerhalb ihrer Profession zu einigen. Es kann nur in ihrem Sinne sein, wenn ihre Arbeit in der Öffentlichkeit akzeptiert und als Teil der politischen Prozesse angesehen wird. Die Unterstützung durch die öffentliche Meinung kann schließlich in vielen Fällen auch ein hilfreiches Druckmittel sein, um eigenen Anliegen Gehör zu verschaffen. Auch im Hinblick auf ihre Zugangsmöglichkeiten bei den Organen der EU ist wichtig, dass die Lobbyisten ein redliches Ansehen genießen, denn dann ist es für den Parlamentarier oder Beamten einfacher, eine kontinuierliche Zusammenarbeit mit inm zu rechtfertigen. Ein seriöser Lobbyist von tadellosem Ruf ist ein starker Verbündeter des Politikers, ihre Kooperation ist für beide von Vorteil und das Ergebnis dieser Zusammenarbeit im Optimalfall ein Gewinn für das Gemeinwohl.

Dieses Argument ist ein wichtiges Element in der Professionalisierungsthese, welche davon ausgeht, dass sich mit der Herausbildung eines eigenen Berufsstandes der Lobbyisten auch zunächst informelle Verhaltensregeln formen, die dann immer mehr an Verbindlichkeit gewinnen. ${ }^{73} \mathrm{Je}$ mehr Lobbyisten als eigene Berufsgruppe angesehen werden, desto präsenter werden sie in der öffentlichen Wahrnehmung und desto größer wird das Interesse an ihrer Arbeit. Negative Schlagzeilen über unrechtmäßiges Verhalten bedeuten dann jedes mal die Gefahr, dass der gesamte Berufsstand in ein schlechtes Licht gerät und sich rechtfertigen muss, wodurch natürlich die eigene Arbeit erschwert wird. Also haben professionelle Lobbyisten ein Interesse daran, dass man sich auf gewisse Mindeststandards einigt, die von allen Kollegen eingehalten werden. „Professionalität soll primär Seriosität markieren und dokumentieren, und diese Seriosität erwächst aus den beruflichen Arbeitsverfahren und Qualitätsstandards, die von der Berufsgruppe kodifiziert und kontrolliert werden" (Lahusen/Jauß 2001: 130). Um die Konturen einer gemeinsamen Identität sichtbar zu machen und eine einheitliche Berufspraxis auszuformen, muss eine professionelle Ethik erarbeitet werden, die dann zu Kontrollfunktionen herangezogen werden kann und allenfalls eine Grundlage für 
die Sanktionierung abweichender, unprofessioneller Tätigkeit liefert. Dass sich das Berufsfeld des Lobbyismus in Brüssel (zwangsläufig) auf dem Weg einer Professionalisierung befindet, darin scheinen sich die meisten Beobachter einig zu sein. ${ }^{74}$ Neben der bereits beschriebenen unübersehbaren Zunahme der Zahl der Lobbyisten in Brüssel - welche Interessen und in welcher Form sie diese vertreten ist hierbei zunächst nebensächlich - ist die Zunahme an spezifischen Ausbildungsgängen dafür ein eindeutiger Hinweis. So existiert in Brüssel z.B. seit 1994 das European Institute for Public Affairs and Lobbying (EIPAL), ein privates Institut, in dem Interessierte in mehrmonatigen Kursen für Lobbyarbeit ausgebildet werden; ein ähnliches Angebot gibt es auch beim EIS Training Centre. ${ }^{75}$

Eine zentrale Funktion in diesem Prozess der Professionalisierung spielen die Berufsverbände, die eine strukturierende Rolle übernehmen und dafür sorgen müssen, aus unkonkreten Willensbekundungen zu mehr Professionalität greifbare Maßnahmen zu formen. Die Erarbeitung eines Verhaltenskodex (code of conduct) hat zum Ziel, die Berufsarbeit nach kollektiv verbindlichen Verhaltensnormen und -regeln zu organisieren und normativ auszurichten. Zu allererst haben solche Kodizes aber eine symbolische Legitimationsfunktion, schließlich haben sie keinen rechtlichen Status. Konkrete Lenkungsfunktionen entstehen erst, wenn die Einhaltung der Standards überwacht wird und ein Zuwiderhandeln mit Sanktionen, z.B. Ausschluss aus dem Berufsverband, bestraft wird. Damit würde auch eine Rufschädigung und damit Wettbewerbsnachteile einhergehen. Vor allem für freischaffende Lobby-Agenturen, die immer wieder neue Aufträge akquirieren müssen, kann sich ein negatives öffentliches Image äußerst nachteilig auf die eigene Marktposition auswirken.

Ob die Selbstreinigungskraft des Marktes tatsächlich ausreicht, um die seriösen von den unseriösen Anbietern zu trennen, ist also die große Frage, und je nach Standpunkt gibt es naturgemäß unterschiedliche Ansichten. Die einen meinen, „[v]om Standpunkt professioneller
Standards erschient dieser Markt durchaus ungeordnet und fehlentwickelt" (Lahusen/Jauß 2001: 137), andere wiederum verlassen sich auf die steuernde Kraft des Wettbewerbes zwischen Agenturen. Auch im Rahmen dieser Arbeit wird diese Frage nicht abschließend beantwortet werden können - nicht zuletzt deshalb, weil dieses Feld immer noch starken Veränderungsprozessen ausgesetzt ist.

Momentan gibt es auf europäischem Niveau zwei erwähnenswerte Berufsverbände für Lobbyisten, SEAP und ECAP. In den 90er Jahren existierten laut Buholzer (1998: 20) noch weitere Zusammenschlüsse von Interessengruppen, die sich aber allem Anschein nach wieder aufgelöst haben. ${ }^{76}$ Auch Greenwood (1997: 84) berichtet von zwei weiteren Organisationen, die zwecks Selbstregulierung gegründet wurden, bezweifelte aber aufgrund der großen Anzahl und Unterschiedlichkeit der Zielgruppe deren Chancen, mehr als nur einen Bruchteil zur Mitgliedschaft bewegen zu können. Diese Vermutung hat sich anscheinend bewahrheitet, denn auch über diese Organisationen lassen sich keinerlei Informationen finden. ${ }^{77}$

Etablieren konnte sich jedoch die Society of European Affairs Professionals, gegründet 1997 u.a. mit dem Ziel, „to comply with its code of conduct which is designed to promote ethical standards in the professional conduct of SEAP members" (s. www.seapweb.agepnet. com). Unter European Affairs Professionals versteht die Organisation "individuals acting on behalf of organizations which have interests to represent in relation to policies, programs and regulatory proposals discussed, decided and implemented within the wide orbit of institutions of the European Union" (ebd.). Laut den Informationen auf der Homepage zählt SEAP momentan 135 Mitglieder, und zwar namentlich aufgeführte Personen, die jeweils für einen Verband, eine Public Affairs-Agentur o. ä. tätig sind. Im Vergleich zu der in Kap. 3.1 genannten Schätzung von in Brüssel als Lobbyisten tätigen Personen muss die Mitgliederbasis als klein betrachtet werden, erst recht wenn man bedenkt, dass die Organisation bereits seit sieben Jahren existiert. 
Es ist somit auch fraglich, wie groß der Einfluss von SEAP auf das Berufsfeld tatsächlich ist und welche Wirkung der code of conduct zu entfalten in der Lage ist. Dieser Verhaltenskodex, der auch auf der Homepage von SEAP zu finden ist, wurde von allen Mitgliedern unterzeichnet und besteht aus folgenden Grundsätzen:

„In their dealings with the EU Institutions, European Affairs professionals shall:

- state their identity (name and organization);

- declare the interest represented;

- neither intentionally misrepresent their status for the nature of their inquiries to officials of the EU Institutions nor create any false impression in relation thereto;

- honor confidential information and embargoes;

- not disseminate false or misleading information knowingly or recklessly and exercise proper care to avoid doing so inadvertently;

- not sell for profit to third parties copies of documents obtained from EU Institutions;

- not obtain any information from European Institutions by illicit or dishonest means;

- avoid any professional conflicts of interests;

- neither directly nor indirectly offer nor give any financial inducement to:

- any EU official, nor

- any member of the European Parliament, nor

- their staff;

- not exert any improper influence on public servants;

- only employ EU personnel subject to the rules, and registration and confidentiality requirements of the EU Institutions."

Die in diesem Verhaltenskodex festgehaltenen Grundregeln sind nicht sehr bemerkenswert, da es sich im Prinzip um selbstverständliche
Leitlinien für den seriösen Umgang in professionellen Zusammenhängen handelt. Und aufgrund fehlender Spezifikationen bezüglich einer Implementierung sowie Beschwerde- und Kontrollmechanismen erscheint der Kodex als zunächst rein appellatives Instrument.

Der code of conduct wurde fast wortwörtlich von einem weiteren Zusammenschluss übernommen, den Public Affairs Practitioners (PAP). $\mathrm{Da}$ dieses Konsortium über keinen eigenen Internet-Auftritt verfügt, sondern nur auf der Homepage der Kommission zu finden ist, konnte deren Status nicht geklärt werden, vermutlich wird es aber vom Generalsekretariat der Kommission verwaltet. ${ }^{78}$ Auch die Bedeutung von PAP scheint sehr gering zu sein, sind doch auf der Mitgliederliste im Internet (s. Fußnote 78) nur 52 Unternehmen, Verbände, Agenturen und ähnliches eingetragen.

Wie in Kap. 3.4 deutlich geworden ist, blickt die Kommission auf eine lange Tradition der Zusammenarbeit mit Interessengruppen zurück, denn diese ermöglicht ihr den Zugang zu unerlässlichen Informationen und garantiert so die Qualität und Erfolgsaussichten ihrer Arbeit. „Dementsprechend möchte die Kommission betonen, dass sie an einem einschließenden Konzept entsprechend dem Grundsatz des offenen Regierens festhält: Jeder Bürger, jedes Unternehmen oder jeder Verband kann die Kommission nach wie vor mit Input versorgen" (Kommission 2002: 11).

Die über lange Zeit gewachsenen Beziehungen zu den organisierten Interessengruppen und die tatsächliche Abhängigkeit externer Expertise machen die Kommission zu einer entschiedenen Vertreterin des Modells der freiwilligen Selbstverpflichtung des Lobbyismus. "[T] mal regulation of lobbying, encouraging the public affairs community to develop its own self-regulatory measures" (Greenwood 2003: 70). Ein Argument dabei ist, dass zuviel Kontrolle die Effizienz des Entscheidungssystems unverhältnismäßig beeinträchtigen würde. Ein „übertrieben legalistischer Ansatz wäre unvereinbar mit der Notwen- 


\section{MINDESTSTANDARDS}

\section{A. Eindeutiger Inhalt der Konsultationsverfahren}

Jegliche Kommunikation im Hinblick auf Konsultationen muss klar und präzise sein und alle notwendigen Informationen enthalten, um Antworten zu erleichtern.

\section{B. Zielgruppe für Konsultationen}

Bei der Bestimmung von Zielgruppen für Konsultationsverfahren muss die Kommission gewährleisten, dass betroffene Parteien Gelegenheit haben, ihren Standpunkt darzulegen.

\section{Veröffentlichung}

Die Kommission muss eine angemessene, auf Sensibilisierung ausgerichtete Werbung gewährleisten und ihre Kommunikationskanäle den jeweiligen Zielgruppen anpassen. Ohne andere Kommunikationsmittel ausschließen zu wollen, sollten öffentliche Konsultationen im Internet veröffentlicht und über die „zentrale Anlaufstelle“ angekündigt werden.

\section{Fristen für die Partizipation}

Die Kommission sollte für Planung und Antworten auf Einladungen und schriftliche Beiträge ausreichend Zeit einräumen. Sie sollte sich bemühen, für Antworten zu schriftlichen öffentlichen Konsultationen eine Frist von mindestens acht Wochen und für Sitzungen eine Frist von 20 Werktagen vorsehen.

\section{E. Eingangsbestätigung und Feedback}

Der Eingang von Beitragen ist zu bestätigen. Die Ergebnisse der öffentlichen Konsultationen sind auf Internetseiten, die über einen Link mit der zentralen Anlaufstelle verbinden sind, zu veröffentlichen. digkeit einer fristgerechten Umsetzung der Politik sowie mit den Erwartungen der Bürger, dass die Europäischen Organe sich mit inhaltlichen Fragen befassen, statt sich auf die Verfahren zu konzentrieren" (Kommission 2002: 10). Inwiefern man solch einer Argumentation folgt, hängt natürlich vom eigenen Standpunkt ab, als zwingende Widerlegung einer Forderung nach gesetzlicher Regelung kann sie jedoch nicht betrachtet werden.

Als ein Ergebnis aus dem Weißbuch „Europäisches Regieren“ (2001) hat die Kommission eine Liste von Mindeststandards ausgearbeitet, um einen Beitrag zur Verbesserung der Konsultationsverfahren zu leisten. Diese Mindeststandards basieren auf den im Weißbuch aufgestellten Kriterien der Partizipation, Offenheit, Verantwortlichkeit, Effektivität und Kohärenz und sind seit 01.01.2003 in Kraft. Veröffentlicht wurden sie in einer Mitteilung der Kommission, außerdem sind sie auf deren Homepage einsehbar. ${ }^{79}$

Die unter den fünf Überschriften (vgl. S. 52) aufgeführten Grundsätze sind jeweils noch durch einige Erläuterungen spezifiziert, die hier jedoch nicht wiedergegeben werden, da es sich nicht um substantielle Ergänzungen handelt. Beachtenswert ist aber das vor dem Hintergrund der in Punkt $\mathrm{C}$ geforderten Veröffentlichung entstandene Internetportal „Ihre Stimme in Europa“, welches es ermöglicht, sich über die laufenden (und bereits abgeschlossenen) Konsultationsverfahren zu informieren. ${ }^{80}$ Dadurch wird auf praktische Weise versucht, einen Beitrag zur Erhöhung der Transparenz der Abläufe in der Kommission zu leisten. Gleichzeitig stellt sich natürlich die Frage, inwiefern tatsächlich alle laufenden Verfahren erfasst werden, bevor hinter den Kulissen eventuell schon Interaktionen stattgefunden haben. Wie in Kap. 4.4 deutlich geworden ist, erleichtert es das unüberschaubare Netzwerk zwischen der Kommission und ihrer Umwelt, im kleinen Rahmen Maßnahmen vorzubereiten.

Um das Verhalten der Interessenvertreter einer gewissen Kontrolle zu unterziehen, verlangte die Kommission die Ausarbeitung eines 
Verhaltenskodex im Zuge einer Selbstregulierung durch die Interessenvertreter. Die dafür von der Kommission vorgelegten Mindestanforderungen an diesen Kodex behandeln nur vier Punkte und müssen als minimal betrachtet werden. Unter den Punkten „Public Presentation“, „Behavior“, „Dissemination of Commission Information“ und "Organizations" werden Punkte aufgeführt, die im Verhaltenskodex zu berücksichtigen sind. ${ }^{81}$ Die Aufforderung einer Selbstregulierung stieß zunächst auf wenig Echo, erst nach der Drohung einer eigenen Ausarbeitung durch die Kommission wurden einige Lobbyisten tätig und erarbeiteten den immer noch gültigen „code of conduct", der weiter oben aufgeführt ist. Dieser stellt die heute gültige Reglementierung der Beziehungen von Interessenvertretern zur Kommission dar, und geht kaum über die ursprünglich minimalen Forderungen der Kommission hinaus. ${ }^{82}$ Die Erfolge der Selbstregulierung können als bescheiden betrachtet werden, oder auch als "wholly unremarkable" (Greenwood 2003: 70), und die Tatsache, dass die Kommission sich mit innen zufrieden gibt, zeigt, wie sehr sie die wohletablierten Beziehungen zu den Interessengruppen nicht gefährden will. ${ }^{83}$

\subsection{Gesetzliche Regulierung}

Dem Modell der Selbstregulierung steht der Ansatz der gesetzlichen Regelung gegenüber, welcher vorsieht, das Feld des Lobbying durch rechtskräftige Gesetze zu reglementieren. Die Vertreter dieses Ansatzes glauben, dass nur rechtlich verbindliche Maßnahmen dazu geeignet sind, den mit Lobbying in der Europäischen Union verbunden Problemen zu begegnen. In ihren Augen haben Selbstregulierungsansätze bis jetzt nicht überzeugen können und müssen eher in der Kategorie „symbolische Legitimation“ verbucht werden, zumindest wenn deren Einhaltung nicht aktiv kontrolliert wird. ${ }^{84}$ Dem Defizit von demokratischer Öffentlichkeit und Kontrolle soll aus dieser Sicht entgegen getreten werden, indem eine zwingende Registrierung aller Lobbyisten eingeführt wird, die den Zugang zu den Institutionen regelt. Damit verbunden wird eine Pflicht der regelmäßigen Berichterstattung über die Aktivitäten der Lobbyisten, ihre Auftraggeber und die aufgewendeten finanziellen Mittel. Vorbild ist oft der „Lobbying Disclosure Act" der USA, der dort 1995 verabschiedet wurde. ${ }^{85}$ Das Gesetz möchte Lobbying nicht verbieten, sondern offen legen, also Transparenz fördern, indem z.B. Abhängigkeitsverhältnisse aufgezeigt und somit nachvollziehbar werden.

Vor dem Hintergrund der in Kap. 4 erarbeiteten Anforderungen an legitimen und demokratischen Lobbyismus erscheinen solcherlei Maßnahmen zwar als gerechtfertigt und - mit Blick auf die EU - in vielen Bereichen auch als wünschenswert. Gleichzeitig muss jedoch auch die Frage gestellt werden, ob es dadurch wirklich möglich wird, die gewünschten Ergebnisse zu erreichen. Denn es drängt sich die Vermutung auf, dass gesetzliche Maßnahmen in vielen Fällen den realen Gegebenheiten hinterherhinken, insofern die tatsächliche Entwicklung des zu regulierenden Praxisfeldes sich laufend neu gestaltet. Ebenfalls kann angenommen werden, dass die betroffenen Akteure Strategien entwickeln, die entgegen den Bestimmungen das Erreichen ihrer Ziele ermöglichen. Gerade die informellen Verfahren im Lobbying zeichnen sich ja dadurch aus, dass sie abseits der offiziellen Wege ansetzen und teils auf andere als die vorgesehenen Mittel zurückgreifen. Sobald das Einhalten der Regeln einen Wettbewerbsnachteil auf dem politischen Basar der EU bedeutet, da deren Durchsetzung nicht effektiv garantiert werden kann, werden sich die Lobbyisten genau überlegen, ob sich regelkonformes Verhalten lohnt. Auch der zu beobachtende Trend hin zu ausgelagerter Interessenvertretung durch Public Affairs-Agenturen trägt dazu bei, dass die Kontrolle erschwert wird, da deren Aktivitäten eher außerhalb von festen Strukturen verlaufen.

Auch eine annähernde Ausgeglichenheit („Waffengleichheit“) bezüglich der vertretenen Interessen, welche im Sinne der Input-Legitimität gefordert wird, ist nur schwer per Gesetz zu erreichen. Denn 
wie bereits erläutert wurde (s. Kap. 4.5), ist die Organisationsfähigkeit öffentlicher Interessen im Vergleich zu privaten geringer, so dass von vornherein ein gewisser „Vorsprung“ privater Interessen in Kauf genommen werden muss. Dennoch können durch gezielte Maßnahmen eventuell die Voraussetzungen für kleinere Organisationen erleichtert werden, eine gewichtigere Stimme zu bekommen. Durch eine „positive Diskriminierung " könnte versucht werden, organisationsschwache Interessen durch finanzielle, strukturelle, organisatorische u.ä. Maßnahmen zu fördern. ${ }^{86}$ Genau dies sieht der Ansatz der assoziativen Demokratie vor, der die gesellschaftliche Ungleichheit politisch korrigieren will. „The core idea of associative democracy is to curb faction through a deliberate politics of association while netting such group contribution to egalitarian-democratic governance" (Cohen/Rogers 1995: 44). Ohne hier näher auf dieses neokorporatistisch angehauchte Konzept eingehen zu können, soll lediglich festgehalten werden, dass die Regulierung bzw. Ausbalancierung von Lobbying einer der primären Ansatzpunkte auf dem Weg zu einer assoziativen Demokratie ist. ${ }^{87}$

In der wissenschaftlichen Diskussion findet man - wenn auch eher vereinzelt - einige Argumente gegen eine gesetzliche Regulierung bzw. für einen Weg der Selbstregulierung durch die Interessenvertreter. So befürchtet Strauch (1993: 102 ff.) durch eine Übertragung von gesetzlichen Regelungen aus Mitgliedstaaten mit anderen institutionellen Hintergründen auf die Brüsseler Ebene eine Gefahr für die Unabhängigkeit der deutschen Verbände. Diese Angst um eine Beschädigung des deutschen korporatistischen Systems durch EUGesetze ist vermutlich eher unbegründet, vor allem geht es ja in der vorliegenden Diskussion um Regelungen für die gemeinschaftliche Ebene, so dass dieses Argument nicht weiter ins Gewicht fällt.

Schwerwiegender sind hingegen die Bedenken von Buholzer (1997: 8), der die Befürchtung äußert, dass bei einer zu strikten Regulierung von Lobbying beim Parlament dieses abhängig würde von „offiziellen“
Informationen, etwa der Kommission oder der Regierungen der Mitgliedstaaten. Im Endeffekt - so Buholzer - könnte dies dazu führen, dass die Informationslage des Parlamentes sich verschlechtern und somit die Qualität seiner Arbeit abnehmen würde. 


\section{Zusammenfassung und Schlussfolgerungen}

Ziel dieser Arbeit war es, ein trotz der gebotenen Kürze aussagekräftiges Bild des Lobbying bei der EU zu zeichnen und gleichzeitig einige der mit diesem Politikelement verbundenen Probleme aufzuwerfen und mögliche Lösungsansätze zu diskutieren. Um eine stichhaltige Einschätzung von Lobbyismus in Brüssel zu erhalten, ist es zunächst unumgänglich, sich dessen Kontext - also die Strukturen und Prozesse des politischen Systems der EU - zu vergegenwärtigen. Zentral ist dabei die Bedeutung des Mehrebenensystems der Union und die Dynamik, die diesem Gebilde innewohnt, also der kontinuierliche Wandel, dem es unterworfen ist. Bei der Gründung der Gemeinschaft war nicht klar, wohin sich diese entwickeln würde, ebenso wenig herrscht heute Einigkeit darüber, ohne dass dies unbedingt als Mangel betrachtet werden muss.

Für das hier interessierende Phänomen der Interessenvertretung hat dieser spezifische Charakter des EU-Systems weitreichende Auswirkungen. Diese können zusammengefasst werden in der Feststellung, dass sich EU-Lobbying teilweise beträchtlich von den Arten der Interessenvertretung in den Mitgliedstaaten unterscheidet. Und zwar handelt es sich dabei nicht bloß um eine Legierung aus den diversen nationalen Formen, sondern um eine gänzlich neue, tatsächlich europäische Form des Lobbying. Diese wird wesentlich bedingt durch die Besonderheiten des institutionellen Aufbaus der EU, die auf Seiten der Interessenvertreter die Entwicklung neuer Strategien und Techniken erforderlich gemacht haben. Die Komplexität des EU-Systems stellt die Interessenvertretung vor neue Herausforderungen, denn um effektiv Einfluss ausüben zu können, muss auf verschiedenen Ebenen und mit jeweils adäquaten Mitteln operiert werden. „Multi-voice“Lobbying ist gefragt, um beim Bargaining in der politischen Arena in Brüssel auf seine Kosten zu kommen. Neben den institutionellen Herausforderungen wird diese Aufgabe dadurch verkompliziert, dass sich eine große Zahl von Teilnehmern um Zugang zu den Informationen und um Gehör für ihre Anliegen bemühen, so dass der Kampf um Aufmerksamkeit eine ständige Komponente in diesem Geschäft ist.

Ganz klar positiv beeinflusst werden die Arbeitsbedingungen von Interessenvertretern durch die Tatsache der relativen Offenheit der EU-Organe, zumindest der hier behandelten, für die gesellschaftlichen Anliegen. Wie gezeigt, erwächst diese Offenheit schlichtweg aus der Angewiesenheit der Beamten und Politiker auf externen Input, vor allem in der Form von Informationen und Expertise, aber auch von politischer Unterstützung und Stimmungsbildern von den Politikadressaten. Die Einbeziehung von Lobbyorganisationen geht so weit, dass diese nicht nur am Rechtsentstehungsprozess teilnehmen, sondern (im Rahmen der Kommission) auch an Exekutiventscheidungen mitwirken können. Es haben sich stellenweise Kooperationsbeziehungen zwischen der Politik und den Interessengruppen etabliert und institutionalisiert, die unter demokratietheoretischer Perspektive fragwürdig sind.

In einem zweiten Schritt wurden deshalb Fragen der Legitimation von Lobbying untersucht, die durch die neue Dimension dieses Phänomens auf europäischer Ebene aufgeworfen werden. Dabei ist deutlich geworden, dass es schwierig ist, nationalstaatliche Legitimationsmodelle ohne Weiteres auf die EU zu übertragen. Dennoch können diese helfen, auf strukturelle Probleme hinzuweisen, auch wenn es dann letztlich eine Frage des Standpunktes bleibt, welche Einwände man gelten lässt und welche man aufgrund der Andersartigkeit der EU für nicht angemessen hält. Es erscheint jedenfalls als unbefriedigend oder zumindest heikel, mit dem Hinweis auf die unvollständige Staatlichkeit der Union herkömmliche Legitimationsmodelle einfach als unpassend abzutun, denn schließlich begreift sich die EU als demokratisches Gebilde. So oder so ist in der Arbeit aber deutlich geworden, dass Lobbying den Ansprüchen nach Transparenz, Offenheit und Repräsentativität genügen muss, um als demokratisch legitimiert 
gelten zu können.

Von einem ausreichenden Maß an Transparenz in Bezug auf die Partizipation von organisierten Interessen bei der Politikgestaltung in der EU kann bis jetzt jedoch noch nicht gesprochen werden. Dafür sind die über Jahrzehnte gewachsenen Strukturen, v.a. im Ausschusswesen der Kommission, noch zu präsent und die Bemühungen nach Offenlegung noch zu schwach. Es ist meist nur schwer nachvollziehbar, welche Akteure zu welchem Zeitpunkt und mit welchem Anteil an der Ausarbeitung neuer Gesetzesvorlagen und anderer Entscheidungen beteiligt sind. Die vorzufindenden Netzwerkstrukturen mögen bezüglich der Effektivität vorteilhaft sein, doch zeichnen sie sich auch durch mangelnde Öffentlichkeit und Sichtbarkeit aus. Dies führt dazu, dass der von der Kommission angestrebte Legitimationsgewinn durch die Einbeziehung möglichst vieler Akteure in die Konsultationsverfahren ausbleibt, denn durch die fehlende Öffentlichkeit kann sich die legitimationsstiftende Wirkung nicht entfalten. Dies liegt aber nicht nur an der Intransparenz der EU, sondern zu einem gewissen Grad auch am mangelnden Verständnis für derlei Vorgänge jenseits der beteiligten Akteure. Auf dem Weg zu einer verstärkten Demokratisierung der Entscheidungsfindung in der EU muss dass hier behandelte Thema in der Öffentlichkeit präsenter werden, wozu die vorliegende Arbeit einen minimalen Beitrag zu leisten hofft.

Auch die Frage der Repräsentativität und Chancengleichheit der vertretenen Interessen konnte nicht abschließend beantwortet werden. Es ist aber deutlich geworden, dass die gegenwärtige Situation die Fortführung der historisch bedingten Dominanz der wirtschaftlichen Interessen begünstigt, auch wenn soziale und ökologische Interessen an Bedeutung gewonnen haben. Bildlich gesprochen ist es nach wie vor so, dass um das Zentrum der EU-Organe, allen voran der Kommission, eine innere Peripherie auszumachen ist, bestehend aus mitgliedsstaatlichen und parteilichen Interessen sowie der Wirtschaftslobby. Öffentliche Interessen und soziale Bewegungen - die
Zivilgesellschaft - sind hingegen in einer äußeren Peripherie angesiedelt, mit entsprechend größeren Schwierigkeiten der Einflussnahme. Erschwerend kommt für die öffentlichen Interessen hinzu, dass sie im Vergleich zu privaten Interessen mit strukturellen Problemen bezüglich ihrer Organisationsfähigkeit zu kämpfen haben. Inwiefern hier von der Politik steuernd eingegriffen werden muss, ist eine offene Frage, die in einem breiteren Kontext untersucht werden muss.

Der dritte Teil der Arbeit befasste sich darauf aufbauend mit der Diskussion, welche Form der Regulierung für EU-Lobbying sinnvoll erscheint. Dass der Bereich der Interessenvertretung in der einen oder anderen Weise reguliert werden sollte, wurde im bisherigen Verlauf der Argumentation deutlich. Dennoch erwies es sich in der EU als äußerst schwierig, sich auf einen gemeinsamen Weg zu einigen, da Differenzen zwischen den Mitgliedstaaten über Sinn und Zweck und die Gefahren von Lobbying fortbestehen bleiben. Außerdem konnte das Definitionsproblem nicht endgültig gelöst werden, und so stellt sich immer noch die Frage, was unter den Begriff Lobbying fallen und somit reguliert werden soll (und kann). Nichtsdestotrotz hat sich in der EU tendenziell eher das Prinzip der Offenlegung von Lobbying gegenüber dem der Kontrolle durchgesetzt, wenn auch in unterschiedlicher Ausprägung. Während die Kommission die Regulierung am liebsten den Interessenvertretern selbst überlassen möchte und auf Selbstverpflichtungen drängt, versucht das Parlament, durch Registrierungs- und Offenlegungspflicht aktiv die Transparenz zu fördern und Missbrauch einzudämmen. So oder so bleibt die Erkenntnis, dass informellen und vor allem unzulässigen Methoden mit Gesetzen nicht immer leicht beizukommen ist. Und damit diese nicht nur einen symbolischen Wert behalten sondern in der Praxis wirksam werden, muss auf beiden Seiten, also bei Lobbying-Akteuren und -Adressaten, der Wille und die Motivation vorhanden sein, unlauteres Verhalten zu bekämpfen und professionelles zu fördern. 


\section{Fussnoten}

${ }^{1}$ Aus Gründen der Lesefreundlichkeit wird darauf verzichtet, jeweils die weibliche und männliche Form zu benutzen, selbstverständlich sind aber immer beide $\mathrm{Ge}-$ schlechter gemeint.

${ }^{2}$ Vgl. Teuber (2001: 20); Leif/Speth (2003a: $\left.10 \mathrm{ff}.\right)$.

${ }^{3}$ Die Begriffe Lobbying und (organisierte) Interessenvertretung werden in dieser Arbeit synonym verwendet.

${ }^{4}$ Vgl. v. Alemann (2000).

${ }^{5}$ Zur Diskussion um das Demokratiedefizit der Europäischen Union und die Frage der demokratischen Legitimation der Union siehe Grande (1996).

${ }^{6} \mathrm{Vgl}$. Thunert (2003).

${ }^{7}$ Vgl. Teuber (2001: 121).

${ }^{8}$ Vgl. Teuber (2001: 146 f.); Europäisches Parlament (2003a: 37).

${ }^{9}$ Vgl. Teuber (2001: 117).

${ }^{10}$ Vgl. Buholzer (1998: 6).

${ }^{11}$ Vgl. Ries (2002: $126 \mathrm{f}$.).

12 Dieser Aspekt der Definition trifft auf das Lobbying bei der Europäischen Union nicht immer zu, wie im Kap. 3 gezeigt werden wird. Gleiches gilt für den letzten der fünf Definitionspunkte.

${ }^{13}$ Vgl. Schunter-Kleemann (2003: 194).

${ }^{14} \mathrm{Vgl}$. Sebaldt (2002: 81).

15 Zu diesem Thema siehe z.B. v. Alemann (2000); Buholzer (1998: 73 ff.); siehe auch Fußnote 23.

${ }^{16}$ Vgl. Buholzer (1998: 8 f.)

17 Vgl. Thunert (2003: 322).

${ }^{18}$ Siehe die verschiedenen Beiträge in Althaus (2001); Ries (2002); Althaus (2002); Kahler/Lianos (2003).

${ }^{19} \mathrm{Vgl}$. Andersen/Woyke (2003: 482).

${ }^{20} \mathrm{Vgl}$. Ronneberger/Rühl (1992: 9 ff.).

${ }^{21}$ So geht es um handfeste finanzielle Konditionen für die Kapitalaufnahme, wenn sich Staaten bei den großen internationalen Rating-Agenturen (z.B. „Standard \& Poor's“, „Moody's“) durch überzeugende Selbstdarstellung um eine gute Einstufung ihrer Bonität bemühen.

22 Vgl. Leif/Speth (2003: 16)

${ }^{23}$ Die klassische (politik)wissenschaftliche Beschäftigung mit organisierter Interessenvertretung geschah vornehmlich im Rahmen von zwei Organisationsmodellen: dem Korporatismus und dem Pluralismus. Im korporatistischen Modell gibt es eine begrenzte Anzahl von Verbänden, die für ihren Bereich über ein Repräsentationsmo- nopol verfügen, hierarchisch gegliedert sind und sich oft durch Zwangsmitgliedschaft konstituieren. Sie arbeiten bei der Politikgestaltung und -umsetzung eng mit dem Staat zusammen und werden teils ziemlich stark von inm kontrolliert. Im pluralistischen Ansatz steht eine unbegrenzte Anzahl von Verbänden um ihre Mitglieder im Wettstreit, es gibt weder staatliche Kontrolle noch Einfluss, und die Willensbildung erfolgt autonom (vgl. Schmitter 1979). Während korporatistische Systeme eher auf Konsens ausgerichtet sind, stehen in pluralistischen Systemen eher Mehrheitsentscheidungen im Vordergrund. Auf eine nähere Befassung mit diesen Ansätzen muss hier verzichtet werden, jedoch wird an entsprechender Stelle auf einzelne Elemente zurückgegriffen.

${ }^{24}$ Vgl. Buholzer (1998: $\left.97 \mathrm{ff}.\right)$.

${ }^{25}$ Vgl. Ries (2002: $125 \mathrm{f}$ ); Teuber 2001: $73 \mathrm{f}$ ); Leif/Speth (2003a: $7 \mathrm{ff}$ ). Außerdem wird folgendes bezeichnende Bonmot kolportiert: „Sag meiner Mutter nicht, dass ich als Lobbyist arbeite - sie glaubt, ich sei Pianist in einem Bordell.“

${ }^{26}$ Ironischerweise hat die Diskussion um die Regulierung von Lobbying in den $\mathrm{Au}$ gen von Greenwood nicht zu einer Verbesserung dessen Ansehens beigetragen, im Gegenteil: „By its entry into the political arena, discussion about the management of interest representation had once again evoked popular images of lobbying as shady deals done in dark corners" (Greenwood 1997: 97).

${ }^{27} \mathrm{Vgl}$. Thunert (2003: $320 \mathrm{ff}$.)

${ }^{28}$ Vgl. von Alemann (2000: 1).

29 So beschreiben etwa Lahusen/Jauß (2001: 162) die Staat-Verbände-Beziehung in den USA als pluralistisch-kompetitiv strukturiert, während sie in der europäischen nationalstaatlichen Politik eher nach konsensuell-deliberativen Mustern (also korporatistisch) organisiert sei.

${ }^{30}$ Siehe z.B. die beiden folgenden Artikel aus der "Public Affairs-Szene“, in denen diese Fragen diskutiert werden: Greve-Grönebaum/von Hayek (o.A.); Vesper (2003).

${ }^{31} \mathrm{Vgl}$. zu den folgenden Ausführungen s. Buholzer (1998: $42 \mathrm{ff.}$.)

32 Vgl. Schunter-Kleemann (2003: 188 f.); Fücks (2003: 56 f.).

${ }^{33} \mathrm{Vgl}$. Lahusen/Jauß (2001: 16)

${ }^{34}$ Vgl. Greenwood (2003: 73).

${ }^{35}$ Aus rein wirtschaftlicher Perspektive kann darunter das Auseinanderbrechen der Produktionskette über nationalstaatliche Grenzen hinweg verstanden werden. Doch gemeinhin wird heutzutage weit mehr darunter gefasst, ohne das dies hier weiter verfolgt werden kann. Siehe z.B. Altvater/Mahnkopf (1997), Schmidt/Trinczek (1999).

${ }^{36}$ Vgl. v. Alemann (2000).

${ }^{37}$ Vgl. Buholzer (1998: 11).

${ }^{38}$ Vgl. van Schendelen (2003: 304); Buholzer (1998: 4).

39 Vgl. Europäisches Parlament (2003: 9) 
${ }^{40}$ Zum Konzept des Mehrebenensystems vgl. Jachtenfuchs/Kohler-Koch (2002: 19 ff.); Nugent (2003: f.).

${ }^{41}$ Mit dem Begriff "venue-shopping“ wird die Entscheidung von Interessengruppen beschrieben, welche politischen Institutionen als Ziel von Lobby-Aktivitäten ausgewählt werden oder in welche Arena die politisch Debatte verlagert wird (vgl. Olson 1990).

${ }^{42}$ Der Mitarbeiterstab der Landesvertretung von Nordrhein-Westfalen in Brüsse umfasst ca. 25 Mitarbeiter, was nicht unbedingt übertrieben erscheint, wenn man bedenkt, dass dieses Bundesland - würde die BRD nicht existieren - das fünftgrößte Mitglied in der EU wäre.

${ }^{43}$ Vgl. Nugent (2003: 281).

${ }^{44}$ Bei UNICE handelt es sich um einen typischen horizontalen, $\mathrm{d}$.h. branchenübergreifenden Verband, während CEFIC einen vertikalen Verband darstellt, dessen Mitglieder-Interessen naturgemäß mehr auf einer Linie liegen (vgl. Fischer 1997: 36 ff.) 45 In ihrem Weißbuch „Europäisches Regieren“ beschreibt die Kommission die Zivilgesellschaft als bestehend aus „Gewerkschaften und Arbeitgeberverbände (.Sozialpartner"), Nichtregierungsorganisationen, Berufsverbände, gemeinnützige Einrichtungen, gesellschaftliche Basisgruppen, Organisationen, über die sich die Bürger am lokalen und kommunalen Leben beteiligen, insbesondere Kirchen und Religionsgemeinschaften" (Kommission 2001: 19, Fußnote 9).

${ }^{46}$ Vgl. Europäisches Parlament 2003a: iv.

47 „Its [Konzentration der Kommission auf starke Interessengruppen, M.B.] effect has been to privilege a small number of better established groups at the expense of a larger number of smaller, newer and/or less institutionalized groups. There is therefore a rise of "secondary lobbying“ - whereby the latter groups lobby others that they believe to have the ear of the Commission“" (Europäisches Parlament 2003a: 39).

${ }^{48} \mathrm{Vgl}$. Teuber (2001: 147)

${ }^{49}$ Nugent (2003: 118) hat ausgerechnet, dass in den Mitgliedstaaten durchschnittlich 300 Beamte pro 10.000 Bürger angestellt sind, während dieses Verhältnis in der EU, alle Institutionen eingerechnet, nur 0,8 zu 10.000 beträgt.

$50 \mathrm{Vgl}$. Eichener (2000: 270 f.).

${ }^{51}$ Vgl. Platzer (2002: 417)

52 Teuber (2001: 127)

53 Vgl. Europäisches Parlament 2003a: 33

${ }^{54}$ Eichener (2000: 268)

${ }^{55} \mathrm{Vgl}$. Eichener (2000: 268)

${ }^{56}$ Platzer (2002: 419) spricht von partizipativer Steuerung und verweist damit auf korporatistische Elemente der EU-Interessenvertretung, die in manchen Bereichen (z.B. Arbeits- Verbraucher- und Umweltschutz, technische Normierung) zu erkennen sind
57 Siehe dazu auch Grande (1996: 345 f.).

${ }^{58} \mathrm{Vgl}$. Teuber (2001: 123).

${ }^{59} \mathrm{Vgl}$. Eichener (2000: 270 f.).

${ }^{60} \mathrm{Vgl}$. Lahusen/Jauß (2001: 205 f.).

61 Auf der Homepage der Kommission können unter folgender Adresse auch alle anderen eingegangenen Stellungnahmen zum Weißbuch konsultiert werden: http:// europa.eu.int/comm/governance/debat_en.htm

62 Vgl. Buholzer (1997: 6).

${ }^{63}$ Kritische Stimmen sprechen - sicherlich überspitzt - vom „Regieren durch Ausschüsse", vgl. Schunter-Kleemann (2003: 188).

${ }^{64}$ Eine besondere Art von Ausschüssen sind die sogenannten Komitologie-Ausschüsse zwischen Rat und Kommission. Sie bestehen aus Mitgliedern der beiden Organe, also aus Kommissionsbeamten und Vertretern der Mitgliedstaaten und begleiten die Verabschiedung von Durchführungsmaßnahmen zu denjenigen Rechtsakten des Rates, für deren Umsetzung die Kommission zuständig ist. Sie dienen also gewissermaßen zur Überwachung der Kommission durch den Rat, oder - neutraler ausgedrückt - der Koppelung der Arbeit der beiden Organe. Die Komitologie ist für Lobbyisten nur indirekt beeinflussbar, wird hier aber dennoch erwähnt, da sie sinnbildlich ist für die Intransparenz mancher EU-Prozesse und immer wieder angeführt wird, wenn vom Demokratiedefizit der Union die Rede ist.

${ }^{65}$ Vgl. Teuber (2001: 145); Buholzer (1997: 8 f.); Leif/Speth (2003: 16).

${ }^{66} \mathrm{Vgl}$. Lahusen/Jauß (2001: 202)

67 Zur Nicht-Rivalität und Nicht-Auschließbarkeit sowie zum Free-Rider-Problem siehe Mankiw (2004: $224 \mathrm{ff}$.).

${ }^{68} \mathrm{Vgl}$. z.B. Lahusen/Jauß (2001: $180 \mathrm{ff}$.).

${ }^{69}$ Lahusen/Jauß (2001: $174 \mathrm{f}$.) sprechen in diesem Zusammenhang auch von „policy communities" und unterscheiden drei Ebenen, auf denen diese existieren können: eine themenbezogene, eine nationalitätsbezogene und eine professionsorientierte Ebene. Gemeinsamkeiten auf eine dieser Ebenen begünstigen die informelle Gruppierung von Akteuren und erleichtern die Zusammenarbeit.

701999 sorgte der Wechsel des EU-Industriekommissars Martin Bangemann zur spanischen Telefongesellschaft Telefonica, wo er als Berater angestellt wurde, für einiges Aufsehen.

71 Da es den Rahmen dieser Arbeit sprengen würde, kann hier nicht im Einzelnen au die Entwicklung und den Verlauf dieser Diskussion eingegangen werden, siehe dazu Greenwood (1997: 80 ff.); Europäisches Parlament (2003a: 31 ff.). Vielmehr wird versucht, die verschiedenen „Knackpunkte“ der Diskussion zu beleuchten und für die Arbeit fruchtbar zu machen.

${ }^{72}$ Für weitere Beispiele siehe Greenwood (1997: 81). 
${ }^{73}$ Vgl. Buholzer (1998: 20 f.); Lahusen(Jauß (2001: 123 ff.).

${ }^{74} \mathrm{Vgl}$. Leif/Speth (2003a: 18).

${ }^{75}$ Siehe www.eipal.be; www.eis-training-centre.be, diese Institution ist hervorgegan gen aus dem European Centre for Public Affairs Brussels (ECPAB); in Berlin wurde dieses Jahr das Deutsche Institut für Public Affairs (DIPA, www.dipa-berlin.org), ein Institut ähnlichen Zuschnitts, gegründet.

76 Über den „European Round Table of Associations and Federations“ (ERAF) und die „Fédérations européenne du Lobbying \& Public Affairs“ (FELPA) konnten im Internet keinerlei Informationen gefunden werden.

77 Es handelt sich um die „European Federation of Lobbyists“ (EFL) und die „European Parliamentary Affairs Lobbyists“ (EPAL). Dass ein Hindernis auf der Suche nach Mitgliedern der Begriff "Lobbyists" im Namen dieser Organisationen ist, kann höchstens vermutet werden.

${ }^{78}$ Siehe:http://europa.eu.int/comm/secretariat_general/sgc/lobbies/code_consultant/ objectpap_en.htm

${ }^{79}$ Siehe Kommission (2002); http://europa.eu.int/comm/secretariat general/sgc/consultation/index_de.htm

${ }^{80}$ Siehe http://europa.eu.int/yourvoice/consultations/index_de.htm

81 Siehe http://europa.eu.int/comm/secretariat general/sgc/lobbies/communication/ annexe2 en.htm\#public

82 Vgl. Teuber (2001: 123).

${ }^{83}$ Vgl. Buholzer (1998: 20)

${ }^{84} \mathrm{Vgl}$. Lahusen/Jauß (2001: 136).

${ }^{85}$ Vgl. Thunert (2003: 325). Das Gesetz und Erläuterungen dazu sind hier veröffentlicht: http://www.senate.gov/pagelayout/legislative/g_three_sections_with_teasers/ lobbyingdisc.htm

${ }^{86} \mathrm{Vgl}$. Huget (2002: 31)

87 Dies würde den zur Verfügung stehenden Rahmen sprengen, weiterführend zum Ansatz der assoziativen Demokratie siehe Cohen/Rogers (1995).

\section{Literaturverzeichnis}

Alemann, Ulrich von (2000): Vom Korporatismus zum Lobbyismus? Die Zukunft der Verbände zwischen Globalisierung, Europäisierung und Berlinisierung. In: Aus Politik und Zeitgeschichte, B 26-27/2000; www.bpb.de/publikationen/G5AS3B,0,0,Vom Korporatismus zum Lobbyismus.html [29.08.04]

Althaus, Marco (2002): Söldner der Politik. Vom Amateur zum Profi: Political Consultants in den USA und Deutschland. In: Becker-Sonnenschein/Schwarzmeier (Hg.), S. 236-260

Althaus, Marco (Hg.) (2001): Kampagne! Neue Strategien für Wahlkampf, PR und Lobbying; Münster: LIT

Altvater, Elmar \& Birgit Mahnkopf (1997): Grenzen der Globalisierung. Ökonomie, Ökologie und Politik in der Weltgesellschaft; Münster: Westfälisches Dampfboot

Becker-Sonnenschein, Stephan \& Manfred Schwarzmeier (Hg.) (2002): Vom schlichten Sein zum schönen Schein? Kommunikationsanforderungen im Spannungsfeld von Public Relations und Politik; Wiesbaden: Westdeutscher Verlag

Benz, Arthur (1997): Policies als erklärende Variable in der politischen Theorie. In: Benz, Arthur \& Wolfgang Seibel (Hg.): Theorieentwicklung in der Politikwissenschaft - eine Zwischenbilanz; Baden-Baden: Nomos

Buholzer, René Paul (1998): Legislatives Lobbying in der Europäischen Union. Ein Kon- zept für Interessengruppen; Bern: Paul Haupt

Bundesrepublik Deutschland (2001): Deutsche Stellungnahme zum Weißbuch der Europäischen Kommission „Europäisches Regieren“; http://europa.eu.int/comm/ governance/contrib_allemagne_en.pdf [29.08.04]

Cohen, Joshua \& Joel Rogers (1995): Secondary associations and democratic govern-ance, in: Cohen, Joshua \& Joel Rogers (Hg.): Associations and Democracy; Lon don: Verso, 7-98

Eichener, Volker (2000): Das Entscheidungssystem der Europäischen Union. Institutionelle Analyse und demokratietheoretische Bewertung; Opladen: Leske + Budrich

Europäisches Parlament (2003a): Working Paper: Lobbying in the European Union - Current Rules and Practices; AFCO 104 EN;

www4.europarl.eu.int/estudies/internet/workingpapers/afco/pdf/104 en.pdf [29.08.04]

Europäisches Parlament (2003b): Ausschuss für Industrie, Außenhandel, Forschung 
und Energie - Entwurf eines Berichtes über die Rolle der europäischen Industriever- bände bei der Festlegung der politischen Maßnahmen der Union; 2202/2264(INI);www.europarl.eu.int/meetdocs/committees/femm/20020709/ 472538DE.pdf [29.08.04]

Fischer, Klemens (1997): Lobbying und Kommunikation in der Europäischen Union; Ber- lin: Berlin Verl. A. Spitz

Fücks, Ralf (2003): Lobbyismus braucht demokratische Kontrolle. In: Leif, Thomas \& Ru- dolf Speth (Hg.), S. 55-59

Grande, Edgar (1996): Demokratische Legitimation und europäische Integration. In: Leviathan, 24. Jg., S. 339-360

Greenwood, Justin (2003): Interest representation in the European Union; London: Palgrave

Greenwood, Justin (1997): Representing Interests in the European Union; London: Macmillan

Greenwood, Justin (o.A.): Do Interest Groups help the EU to reach its Citizens? www.euractiv.com/ndbtext/pa/euractivarticlebyjustingreenwood.pdf [29.08.04]

Greve-Grönebaum, Katrin \& Stephanie von Hayek (o.A.): Public Relations, Public Affairs und Lobbyismus: Brauchen wir neue Spielregeln für die Berliner Republik? www.bridges.de/Download/Diskussionspapier_030902.pdf [29.08.04]

Habermas, Jürgen (1962): Strukturwandel der Öffentlichkeit. Untersuchungen zu einer Kategorie der bürgerlichen Gesellschaft; Darmstadt: Luchterhand

Hart, Thomas (2003): Mehr Transparenz für die stillen Mächtigen. In: Leif, Thomas \& Rudolf Speth (Hg.), S. 60-84

Huget, Holger (2002): Europäische Mehrebenen-Demokratie? Dezentrale Steuerung und demokratische Legitimation am Beispiel europäischer Beschäftigungspolitik; WIP Occasional Paper Nr. 18, Eberhard-Karls-Universität Tübingen; http://w210 ub.uni-tuebingen.de/dbt/volltexte/2002/539/pdf/WIP-18.pdf [29.08.04]

Jachtenfuchs, Markus \& Beate Kohler-Koch (2002): Governance in der Europäischen Union; erscheint in: Benz, Arthur (Hg.): Governance. Eine Einführung; Opladen: Leske + Budrich; www.iu-bremen.de/imperia/md/ content/faculty/mjachtenfuchs/ goveu.pdf [29.08.04]

Kahler, Tobias \& Manuel Lianos (2003): Neue Aktionsfelder: Agenturen in den LobbyKinderschuhen. In: Leif/Speth (Hg.), S. 335-349

Kommission der Europäischen Gemeinschaften (2001): Europäisches Regieren. Ein Weißbuch; KOM(2001) 428 endg.; http://europa.eu.int/comm/employment_social/fundamental_rights/pdf/civsoc/whitepap_de.pdf [29.08.04\}
Kommission der Europäischen Gemeinschaften (2002): Mitteilung der Kommission: Hin zu einer verstärkten Kultur der Konsultation und des Dialogs - Allgemeine Grundsätze und Mindeststandards für die Konsultation betroffener Parteien durch die Kommission; KOM(2002) 704 endg.; http://europa.eu.int/eur-lex/de/com/ cnc/2002/com2002_0704de01.pdf [29.08.04]

Lahusen, Christian \& Claudia Jauß (2001): Lobbying als Beruf. Interessengruppen in der Europäischen Union; Baden-Baden: Nomos

Leif, Thomas \& Rudolf Speth (2003a): Anatomie des Lobbyismus. Einführung in eine unbekannte Sphäre der Macht. In: Leif/Speth (Hg.), S. 7-32

Leif, Thomas \& Rudolf Speth (Hg.) (2003b): Die stille Macht. Lobbyismus in Deutschland; Wiesbaden: Westdeutscher Verlag

Mankiw, N. Gregory (2004): Principles of Economics; Mason: Thomson South-Western

Nugent, Neill (2003): The Government and Politics of the European Union; Basingstoke: Palgrave Macmillan

Olson, Mancur (1968): Die Logik des kollektiven Handelns - Kollektivgüter und die Theorie der Gruppen; Tübingen: Mohr

Olson, Susan Marie (1990): Interest Group Litigation in Federal District Court. In: Journal of Politics; Vol. 52, S. 854-882

Platzer, Hans-Wolfgang (2002): Interessenverbände und europäischer Lobbyismus. In: Weidenfeld, Werner (Hg.): Europa-Handbuch; Gütersloh: Bertelsmann Stiftung, S. 409-422

Ries, Florian (2002): Lobbyismus in der globalisierten Mediengesellschaft. Über die Rolle von PR-Agenturen im politischen Gestaltungsprozess. In: Becker-Sonnenschein/Schwarzmeier (Hg.), S. 125-138

Ronneberg, Franz \& Manfred Rühl (1992): Theorie der Public Relations: ein Entwurf; Opladen: Westdeutscher Verlag

Scharpf, Fritz W. (1999): Regieren in Europa: Effektiv und demokratisch? Frankfurt a.M.: Campus

Schendelen, Rinus van (2003): Brussels: The premier league of lobbying. In: Leif/Speth (Hg.), S. 300-319

Schmidt, Gert \& Rainer Trinczek (Hg.) (1999): Globalisierung. Ökonomische und soziale Herausforderungen am Ende des zwanzigsten Jahrhunderts; Baden-Baden: Nomos

Schmitter, Philippe C. (1979): Still the Century of Corporatism? In: Schmitter, Philippe C. \& Gerhard Lehmbruch (Hg.): Trends towards corporatist intermediation; 
London: Sage

Schunter-Kleemann, Susanne (2003): Seilschaften und andere „Verstrickungen“: Zur poli- tischen Kultur der Europäischen Union. In: Scharenberg, Albert \& Oliver Schmidtke (Hg.): Das Ende der Politik? Globalisierung und der Strukturwandel des Politischen; Münster: Westfälisches Dampfboot, S. 182-207

Sebaldt, Martin (2002): Interessengruppen und Öffentlichkeitsarbeit - eine gestörte Beziehung? Muster und Probleme der „PR“ deutscher Verbände. In: Becker-Sonnenschein/Schwarzmeier (Hg.), S. 81-104

Strauch, Manfred (Hg.) (1993): Lobbying. Wirtschaft und Politik im Wechselspiel; Wiesbaden: Gabler

Teuber, Jörg (2001): Interessenverbände und Lobbying in der Europäischen Union; Frankfurt a.M.: Peter Lang

Thunert, Martin (2003): Is that the way we like it? Lobbying in den USA. In: Leif/Speth (Hg.), S. 320-334

Vesper, Sebastian (2003): Richtlinien gesucht; PR Report, 05/Mai 2003, S. 30-31; www.degepol.de/downloads/PR030_31_0503.pdf [29.08.04]

Weidenfeld, Werner (Hg.) (2002): Europa-Handbuch; Gütersloh: Bertelsmann Stiftung

\section{BASLER SCHRIFTEN ZUR EUROPÄISCHEN INTEGRATION}

O Wir bestellen die Schriftenreihe im Jahresabonnement zu CHF 120.-. Das Abonnement verlängert sich automatisch um ein Jahr, wenn es nicht drei Monate vor Ablauf schriftlich gekündigt wird.

O Wir bestellen folgende Nummern zum Preis von CHF 20.- (Doppelnr 30.)

O Wir sind an einem Publikationsaustausch interessiert.

O Wir sind an Weiterbildungs-Unterlagen (Nachdiplomkurs) interessiert.

* vergriffen

O Nr. 1 Subsidiarität - Schlagwort oder Kurskorrektur (mit Beiträgen von Flavio Cotti, Jean-Paul Heider, Jakob Kellenberger und Erwin Teufel) (Doppelnummer)*

ONr. 2 Ein schweizerisches Börsengesetz im europäischen Kontext (Tagungsband/Doppelnummer)*

O Nr. 3 Martin Holland, The European Union's Common Foreign and Security Policy: The Joint Action Toward South Africa*

O Nr. 4 Brigid Gavin, The Implications of the Uruguay Round for the Common Agricultural Policy

ONr. 6 Urs Saxer, Die Zukunft des Nationalstaates

ONr. 7 Frank Emmert, Lange Stange im Nebel oder neue Strategie? Die aktuelle Rechtsprechung des EuGH zur Warenverkehrsfreiheit

ONr. 8 Stephan Kux, Subsidiarity and the Environment: Implementing International Agreements

O Nr. 9 Arbeitslosigkeit (mit Beiträgen von Christopher Boyd, Wolfgang Franz und Jean-Luc Nordmann)

O Nr.10 Peter Schmidt, Die aussenpolitische Rolle Deutschlands im neuen Europa

O Nr.11 Hans Baumann, Möglichkeiten und Grenzen der Sozialen Dimension nach Maastricht: Das Beispiel der Bauwirtschaft *

O Nr.12 Georg Kreis, Das schweizerische Staatsvertragsreferendum: Wechselspiel zwischen indirekter und direkter Demokratie 
ONr.13 Markus Lusser, Die europäische Währungsintegration und die Schweiz

ONr.14 Claus Leggewie, Ist kulturelle Koexistenz lernbar?

O Nr.15 Rolf Lüpke, Die Durchsetzung strengerer einzelstaatlicher Umweltschutznormen im Gemeinschaftsrecht (Doppelnummer)

ONr.16 Stephan Kux, Ursachen und Lösungsansätze des Balkankonflikts: Folgerungen für das Abkommen von Dayton

ONr.17 Jan Dietze/Dominik Schnichels, Die aktuelle Rechtssprechung des Europäischen Gerichtshofes zum Europäischen Gerichtsstands- und Vollstreckungsübereinkommen (EuGVÜ)

O Nr.18 Basler Thesen für die künftige Verfassung Europas (2. Aufl.)

O Nr.19 Christian Garbe, Subsidiarity and European Environmental Policy: An Economic Perspective

O Nr.20 Claudia Weiss, Die Schweiz und die Europäische Menschenrechtskonvention: Die Haltung des Parlaments 1969-1995

ONr.21 Gunther Teubner, Globale Bukowina: Zur Emergenz eines transnationalen Rechtspluralismus

O Nr.22 Jürgen Mittelstrass, Stichwort Interdisziplinarität (mit einem anschliessenden Werkstattgespräch)

ONr.23 William James Adams, The Political Economy of French Agriculture

O Nr.24 Aktuelle Fragen der Wirtschafts- und Währungsunion (mit Beiträgen von Gunter Baer, Peter Bofinger, Renate Ohr und Georg Rich) (Tagungsband/Doppelnummer)

O Nr.25 Franz Blankart, Handel und Menschenrechte

O Nr.26 Manfred Dammeyer/Christoph Koellreuter, Die Globalisierung der Wirtschaft als Herausforderung an die Regionen Europas

O Nr.27 Beat Sitter-Liver, Von Macht und Verantwortung in der Wissenschaft

O Nr.28 Hartwig Isernhagen, Interdisziplinarität und die gesellschaftliche Rolle der Geistes- und Kulturwissenschaften

O Nr.29 Muriel Peneveyre, La réglementation prudentielle des banques dans I'Union Européenne

ONr.30 Giuseppe Callovi/Roland Schärer/Georg Kreis, Citoyenneté et naturalisations en Europe
O Nr.31 Peter Häberle, Gemeineuropäisches Verfassungsrecht

O Nr.32 Jacques Pelkmans, Europe's Rediscovery of Asia. Political, economic and institutional aspects

O Nr.33 Maya Krell, Euro-mediterrane Partnerschaft. Die Chancen des Stabilitätstransfers

O Nr.34 Valéry Giscard d'Estaing, L'Union Européenne: Elargissement ou approfondissement?

O Nr.35 Martin Holland, Do Acronyms Matter? The Future of ACP-EU Relations and the Developing World

O Nr.36 Andreas Guski, Westeuropa - Osteuropa: Aspekte einer problematischen Nachbarschaft

O Nr.37 Matthias Amgwerd, Autonomer Nachvollzug von EU-Recht durch die Schweiz - unter spezieller Berücksichtigung des Kartellrechts (Doppelnr.)

O Nr.38 Manfred Rist, Infotainment oder Sachinformation? Die Europäische Union als journalistische Herausforderung (Doppelnummer)

O Nr.39 Lothar Kettenacker/Hansgerd Schulte/Christoph Weckerle, Kulturpräsenz im Ausland. Deutschland, Frankreich, Schweiz

O Nr.40 Georg Kreis/Andreas Auer/Christoph Koellreuter, Die Zukunft der Schweiz in Europa? Schweizerische Informationstagung vom 15. April 1999 veranstaltet durch das EUROPA FORUM LUZERN

O Nr.41 Charles Liebherr, Regulierung der audiovisuellen Industrie in der Europäischen Union

ONr.42/3 Urs Saxer, Kosovo und das Völkerrecht. Ein Konfliktmanagement im Spannungsfeld von Menschenrechten, kollektiver Sicherheit und Unilateralismus

O Nr.44/5 Gabriela Arnold, sollen Parallelimporte von Arzneimitteln zugelassen werden? Eine Analyse der Situation in der Europäischen Union mit Folgerungen für die Schweiz

ONr.46 Markus Freitag, Die politischen Rahmenbedingungen des Euro: Glaubwürdige Weichenstellungen oder Gefahr möglicher Entgleisungen?

O Nr.47/8 Andrew Watt, „What has Become of Employment Policy?“ - Explaning the Ineffectiveness of Employment Policy in the European Union 
O Nr.49 Christian Busse, Österreich contra Europäische Union - Eine rechtliche Beurteilung der Reaktionen der EU und ihrer Mitgliedstaaten auf die Regierungsbeteiligung der FPÖ in Österreich

O Nr.50 Thomas Gisselbrecht, Besteuerung von Zinserträgen in der Europäischen Union - Abschied vom Schweizerischen Bankgeheimnis?

O Nr.51 Uta Hühn, Die Waffen der Frauen: Der Fall Kreil - erneuter Anlass zum Konflikt zwischen europäischer und deutscher Gerichtsbarkeit? EuGH, Urteil vom 11.1.2000 in der Rs. C-283/98, Tanja Kreil/BRD

O Nr.52/3 Thomas Oberer, Die innenpolitische Genehmigung der bilateralen Verträge Schweiz - EU: Wende oder Ausnahme bei aussenpolitischen Vorlagen?

O Nr.54 Georg Kreis, Gibraltar: ein Teil Europas - Imperiale oder nationale Besitzansprüche und evolutive Streiterledigung.

O Nr.55 Beat Kappeler, Europäische Staatlichkeit und das stumme Unbehagen in der Schweiz. Mit Kommentaren von Laurent Goetschel und Rolf Weder.

O Nr.56 Gürsel Demirok, How could the relations between Turkey and the European Union be improved?

O Nr.57 Magdalena Bernath, Die Europäische Politische Gemeinschaft. Ein erster Versuch für eine gemeinsame europäische Aussenpolitik

O Nr.58 Lars Knuchel, Mittlerin und manches mehr. Die Rolle der Europäischen Kommission bei den Beitrittsverhandlungen zur Osterweiterung der Europäischen Union. Eine Zwischenbilanz

O Nr.59 Perspektiven auf Europa. Mit Beiträgen von Hartwig Isernhagen und Annemarie Pieper

O Nr.60 Die Bedeutung einer lingua franca für Europa. Mit Beiträgen von Georges Lüdi und Anne Theme

O Nr.61 Felix Dinger, What shall we do with the drunken sailor? EC Competition Law and Maritime Transport

O Nr.62 Georg F. Krayer, Spielraum für Bankegoismen in der EU-Bankenordnung

O Nr.63 Philippe Nell, China's Accession to the WTO: Challenges ahead

O Nr.64 Andreas R. Ziegler, Wechselwirkung zwischen Bilateralismus und
Multilateralismus Das Beispiel der Freihandelsabkommen der EFTAStaaten

O Nr.65 Markus M. Haefliger, Die europäische Konfliktintervention im burundischen Bürgerkrieg, („Arusha-Prozess“)von 1996 bis 2002

O Nr.66 Georg Kreis (Hrsg), Orlando Budelacci (Redaktion): Der Beitrag der Wissenschaften zur künftigen Verfassung der EU. Interdisziplinäres Verfassungssymposium anlässlich des 10 Jahre Jubiläums des Europainstituts der Universität Basel.

O Nr.67 Francis Cheneval, Die Europäische Union und das Problem der demokratischen Repräsentation.

O Nr.68 Politik und Religion in Europa. Mit Beiträgen von Orlando Budelacci und Gabriel N. Toggenburg.

O Nr.69 Chantal Delli, Das Wesen der Unionsbürgerschaft, Überlegungen anhand des Falls Rudy Grzelczyk gegen Centre public d'aide sociale d'Ottignies-Louvain-la-Neuve.

O Nr.70 Federica Sanna, La garantie du droit de grève en Suisse et dans la L'Union européenne.

O Nr.71 Elze Matulionyte, Transatlantic GMO Dispute in the WTO: WIII Europe futher abstain from Frankenstein foods?

ONr.72 Rolf Weder (Hrsg.) Parallelimporte und der Schweizer Pharmamarkt

Europainstitut der Universität Basel, Gellertstrasse 27, CH-4020 Basel, Schweiz, Tel. ++41 (0) 6131797 67, FAX ++41 (0) 613179766 E-mail: europa@unibas.ch, Internet: www.europa.unibas.ch

(c) Europainstitut der Universität Basel 2005 